Research Article

\title{
Comparative and Equilibrium Studies on Anionic and Cationic Dyes Removal by Nano-Alumina-Doped Catechol Formaldehyde Composite
}

\author{
V. Karthik, ${ }^{1}$ P. Selvakumar, ${ }^{2}$ N. Sivarajasekar $\mathbb{D}^{3},{ }^{3}$ P. Megavarshini, ${ }^{1}$ N. Brinda, ${ }^{1}$ \\ J. Kiruthika, ${ }^{1}$ K. Balasubramani, ${ }^{4}$ Tansir Ahamad, ${ }^{5}$ and Mu. Naushad ${ }^{5}{ }^{5}$ \\ ${ }^{1}$ Department of Industrial Biotechnology, Government College of Technology, Coimbatore 641013, TN, India \\ ${ }^{2}$ Department of Chemical Engineering, School of Mechanical, Chemical and Materials Engineering, \\ Adama Science and Technology University, Adama 1888, Ethiopia \\ ${ }^{3}$ Laboratory for Bioremediation Research, Unit Operations Laboratory, Department of Biotechnology, \\ Kumaraguru College of Technology, Coimbatore, TN, India \\ ${ }^{4}$ Department of Petrochemical Engineering, JCT College of Engineering and Technology, Coimbatore, TN, India \\ ${ }^{5}$ Department of Chemistry, College of Science, King Saud University, Riyadh, Saudi Arabia
}

Correspondence should be addressed to N. Sivarajasekar; sivarajasekar@gmail.com and Mu. Naushad; naushadksu@ rediffmail.com

Received 7 May 2020; Revised 6 September 2020; Accepted 12 September 2020; Published 26 September 2020

Academic Editor: Khaled Mostafa

Copyright $(2020$ V. Karthik et al. This is an open access article distributed under the Creative Commons Attribution License, which permits unrestricted use, distribution, and reproduction in any medium, provided the original work is properly cited.

\begin{abstract}
Nano-alumina-doped catechol formaldehyde polymeric composite was prepared, characterized, and applied as an adsorbent for the removal of an anionic dye Congo red (CR) and a cationic dye SafraninO (SF), by adsorption process especially from aqueous solutions. Characterizations such as particle size distribution, zeta potential, BET, FTIR, and FESEM-EDAX were carried out for the adsorbent prepared. All experiments were conducted at the batch condition to study the effects of initial dye concentration (CR: $30-90 \mathrm{mg} / \mathrm{L}$ and SF: $10-50 \mathrm{mg} / \mathrm{L}), \mathrm{pH}(2-11)$, temperature $\left(25-55^{\circ} \mathrm{C}\right)$, and adsorbent dosage $(0.05-0.3 \mathrm{~g})$ on dye removal. The isotherm models (Langmuir, Freundlich, and Temkin) were analyzed for this adsorption work. The kinetic data obtained were analyzed by the pseudo-first-order, pseudo-second-order, Bangham, and Chien-Clayton equations. Dyes adsorption data were well fitted with the Freundlich isotherm equilibrium model and the pseudo-second-order kinetic model. Study results suggested that the nano-alumina-polymeric composite could be an effective adsorbent for anionic dye rather than cationic dye.
\end{abstract}

\section{Introduction}

Dyes are color-forming complex compounds and naturally get adsorbed over the surface of the substrate. Because of this property, it has majorly been used for various industrial applications such as textiles, cosmetics, pulp, and paper, and so on [1-4]. Generally, the dyes are classified into two main groups, namely natural dyes and synthetic dyes. Anionic and cationic dyes come under the category of synthetic dyes, and cationic dyes are significantly more harmful than the other one $[5,6]$. It is estimated that the amount of dyes used all over the world to be in the range of 10,000 tons per year [7]. Owing to the increase in population, the usage of dyes in the industries has also been elevated.

Even though industries have many advanced eco-friendly technologies and recycling techniques for treating wastewater, the entire dyes present in the sewer could not entirely be eliminated. It is well documented that CR is a highly watersoluble dye and a significant pollutant in the wastewater draining from the textile, pulp and paper, printing, and dyeing industries [8]. SF is a basic azo dye and water-soluble synthetic dye. It has majorly been used in the dyeing of leather, fibers, cotton, wool, paper, and silk. Because of its over usage 
as a colorant in many industries, it acts as a model compound for dyes. These widely used dyes are major hazardous to the environment and also cause severe illnesses such as skin allergies, tumor, and mutation to humans $[9,10]$.

These dyes are nonbiodegradable, and thus, typical conventional practices are not sufficient to eliminate them. As a result, various physicochemical approaches were developed for taking them away from wastewater. But neither of the techniques was fruitful in providing complete removal of dyes in wastewater $[11,12]$. As the adsorption technique has high-quality treatment processes, it was favored for the expulsion of toxins, for example, dyes. Also, this technique is most desirable for dye removal because of its smooth operation, simpler design setup [13-19].

This procedure, for the most part, comprises two principle segments viz., adsorbent and adsorbate. Adsorbates are referred to as dyes in the fluid, while adsorbents are the substances added to the dye solution to capture the coloring complexes $[20,21]$. Some of the research outcomes revealed that the production of adsorbents from different low-cost materials such as clays, agricultural waste (rice husk, maize cob, and coconut shell), siliceous materials (perlite, silica beads, and alunite), zeolites, metal oxides (iron and alumina), and others (chitosan, starch, and cotton as biosorbents) is making this process inexpensive $[15,22]$. Among them, the polymer composites have majorly been preferred and considered as adsorbents to remove the synthetic dyes from the sewer [23-27]. Since it is more effective in the process, thereby, it could contribute to resolving water pollution problems [28].

Although several studies have been reported on the polymeric composite adsorbents for separating the dyes from the wastewater, doping of any of the adsorbent material in a polymeric matrix followed by carbonization and activation makes polymeric composite adsorbents [29-31]. At this stage, there is still a need of more investigations on polymeric composite adsorbents on dye removal to make this process more effective and commercial. So far, no study has been carried out to remove the commercial dyes, namely $\mathrm{CR}$ and SF, in the wastewater using Alumina Polymeric Composite (APC). Hence, the present study was aimed to prepare alumina nanoparticle adsorbent doped with catechol formaldehyde resin and used as an adsorbent to check its feasibility in the dye removal. This polymeric composite adsorbent was prepared by the suspension polymerization technique [32]. CR, an anionic dye and SF, a cationic dye, were selected to evaluate the adsorption efficiency of prepared alumina polymeric matrix composite in the aqueous solutions [33-36]. The equilibrium data obtained were examined using different kinetic and isotherm models to understand the adsorption mechanism.

\section{Materials and Methods}

2.1. APC Preparation. A sterile $250 \mathrm{~mL}$ beaker contains catechol $(50 \mathrm{~g})$ with few drops of water was heated at $150^{\circ} \mathrm{C}$ till the catechol switched over to the molten state. To that, $63 \mathrm{~mL}$ of formaldehyde solvent (37\%), $1.5 \mathrm{~mL}$ of triethylamine and $3.5 \mathrm{~g}$ of hexamine were added and continuously stirred for
30 min for proper mixing. In this reaction, triethylamine acts as a catalyst, while hexamine acts as a cross-linking agent among the catechol and formaldehyde. Subsequently, the reaction mixture was heated at $31^{\circ} \mathrm{C}$ for $40 \mathrm{~min}$ until the solution turned into the whitish-yellow color emulsion. A $3 \mathrm{~g}$ of polyvinyl alcohol (PVA), a stabilizing agent, and $0.5 \mathrm{~g}$ of aluminum oxide were added to the whitish-yellow color emulsion within $15 \mathrm{~min}$ and continuously heated until it turns into a crystalline state. Then, the crystals were cooled by keeping them for $8 \mathrm{~h}$ at room temperature. The prepared crystal was washed twice with deionized water, acetone, and ethanol separately and placed in a hot air oven to remove moisture content. The dried crystals (i.e., APC) were made into powdered form with uniform particle size and utilized as an adsorbent for further experiments. The synthesized APC was characterized using particle size analyzer, zeta potential, BET (Brunauer-Emmett-Teller) analysis, FTIR (Fourier transform infrared spectroscopy), and FESEM-EDAX (field emission scanning electron microscopy with energy dispersive X-ray spectroscopy).

2.2. Batch Experiment. The $\mathrm{pH}$ of working dye solutions of $\mathrm{CR}$ and $\mathrm{SF}$ dyes were adjusted into $\mathrm{pH} 2$ and $\mathrm{pH} 10$, respectively, by adding $0.5 \mathrm{M} \mathrm{HCL}$ and $0.5 \mathrm{M} \mathrm{NaOH}$. About $0.1 \mathrm{~g}$ of APC was added into $25 \mathrm{~mL}$ of each dye solution, the flask was covered with coil and kept in an orbital shaker at $200 \mathrm{rpm}$ for different time intervals. After the desired time was attained, the mixture of dye solution with APC was filtered and the optical density of filtrate was examined by using UV-Spectrometer (Shimadzu UV-vis 2550, Japan) to determine the adsorption efficiency, i.e., the concentration of solution after adsorption. A similar procedure was continued to evaluate the effects of various experimental parameters such as initial dye concentration, $\mathrm{pH}$ of the dye solutions, process temperature, and contact time for the different regular intervals. The removal percentage of dyes calculated using the following equation:

$$
\% R=\frac{C_{i}-C_{0}}{C_{i}} \times 100,
$$

where $C_{i}$ and $C_{0}\left(\mathrm{mg} \mathrm{l}^{-1}\right)$ are initial and final concentrations of the dyes in the aqueous solution. The dye adsorption capacity $q_{\mathrm{t}}(\mathrm{mg} / \mathrm{g})$ at any time $t$, was determined as follows:

$$
q_{\mathrm{t}}=\left(C_{i}-C_{\mathrm{t}}\right) \times \frac{V}{M},
$$

where $C_{\mathrm{t}}(\mathrm{mg} / \mathrm{L})$ is the concentration of dye at any time $t, V$ (L) is the volume of dye solution, and $M(\mathrm{~g})$ is the amount of APC. The exhausted APC was rejuvenated using acetone, hot water, dilute $\mathrm{HCl}$, dilute $\mathrm{NaOH}$ solution, and dilute $\mathrm{NaCl}$ solution in order to find a suitable regenerating solvent.

\section{Results and Discussion}

3.1. Characterization of the Adsorbent. The particle size of synthesized alumina doped polymeric composites was determined after the carbonization and activation for different systematic time intervals $(60,90$, and $120 \mathrm{~min})$ at $400^{\circ} \mathrm{C}$. The 
measured particle size for 60,90 , and 120 min carbonized material was found to be $651.4,525.5$, and $503.7 \mathrm{~nm}$, respectively. The results showed that $120 \mathrm{~min}$ carbonized material produced small-sized particles when compared to short-time heat exposed materials. The observed effects on the variation of particle sizes were similar to the study outcomes reported elsewhere [37]. The particle size distribution of APC after carbonization at $400^{\circ} \mathrm{C}$ for $120 \mathrm{~min}$ analyzed by a particle size analyzer is represented in Figure 1(a). Further experiments in this study were carried out with the materials carbonized at $400^{\circ} \mathrm{C}$ for $120 \mathrm{~min}$ exposure time.

Figure 1(b) impersonates the values of zeta potential, from which the surface charge of the APC is determined. Up to $\mathrm{pH} 6.5$, the APC zeta potential value diminished precisely. Then the value continually decreased for the increase in $\mathrm{pH}$ and after the $\mathrm{pH}$ value reached 9.0, the zeta potential value decreased rapidly. From these results, it was decided that the isoelectric point of the APC is 6.0. This depicted that the layer of the adsorbent charged negatively and it expedited the positive (cationic) species. Similarly, the solution $\mathrm{pH}$ value exceeds 6.0, then the surface layer of the adsorbent positively charged and it expedited the negative (anionic) species. This explained the effective adsorption of anionic dye $C R$ in a medium that has acidic nature, whereas the cationic dye SF showed efficient adsorption in a medium that has basic nature.

The BET analysis is mostly used to determine the definitive exterior area, from which the size of the pores can also be estimated. This data is also very useful to anticipate the dissolution rate since the definitive exterior area is proportional to the dissolution rate. From the BET analysis, the following information was obtained: the initial pore volume $\left(0.947 \mathrm{~cm}^{3} / \mathrm{g}\right)$, average pore diameter $(2.76 \mathrm{~nm})$, BET surface area $\left(2.781 \mathrm{~m}^{2} / \mathrm{g}\right)$, and monolayer volume $\left(0.2434 \mathrm{~cm}^{3} / \mathrm{g}\right)$.

The FTIR analysis is an important technique that gives the information on functional groups of various compounds and helps to identify the chemical structural changes of polymeric, organic, and inorganic materials. The response of functional groups to IR rays may fluctuate over a wide range, depending on the interaction of atoms within the molecule. Hence, the infrared light range $400-4000 \mathrm{~cm}^{-1}$ was utilized to examine the test samples and look out the chemical properties in the FTIR investigation. The observed FTIR spectra of the composite before and after the adsorption of two different dyes are illustrated in Figure 2. It can be seen from Figure 2(a) that adsorption bands between the range 3500 to $4000 \mathrm{~cm}^{-1}$ for the APC before adsorption indicated the presence of many aromatic groups clustered to form the polymeric matrix. In the same image, it can be observed that the peak around the $500 \mathrm{~cm}^{-1}$ region showed the presence of alumina in the APC. The broad FTIR peak at $3500 \mathrm{~cm}^{-1}$ range represents $\mathrm{O}-\mathrm{H}$ stretching; the peak at $3685 \mathrm{~cm}^{-1}$ indicates the presence of phenolic $\mathrm{O}-\mathrm{H}$ group in the composite before adsorption. The medium broad band observed at the range $600-800 \mathrm{~cm}^{-1}$ of spectra of APC after adsorption was due to the frequency of azo group, amine group in CR dye and C-S stretching, and methyl group in SF dye.
Similar results were observed on the adsorption study of cationic and anionic dyes on polymer-modified yeast adsorbents [38]. The adsorption peak at $1652 \mathrm{~cm}^{-1}$ range is attributed to the stretching vibration of $\mathrm{C}=\mathrm{O}$.

The FESEM is used to characterize the surface morphology of APC before and after the adsorption dyes, and the observed results are shown in Figures 3(a)-3(c). The outcomes of FESEM analysis revealed that tested samples (APC) were cylindrical rod-shaped with a size range of 500-800 nm. As depicted in Figure 3(a), the FESEM image of APC illustrated that pores were formed well on the matrix with alumina incorporated polymeric materials. It also confirmed that alumina was well embedded with the polymeric matrix and homogeneously spread over the porous surface of the catechol and formaldehyde matrix cross-linked by hexamine. Similar observations were also documented in the analysis of magnetic oxide embedded bentonite clay for $\mathrm{Cr}$ (III) adsorption [39]. The well-impregnated and distributed small-sized alumina particles on the polymer matrix could make a considerable increase in the surface area of APC. It would be an indicative measure of a suitable adsorbent for adsorbing more dyes in the process. The adsorption of dyes created distinct changes in the physical structure of the materials taken. The FESEM images after dye adsorption indicated that the nonporous structure was due to the presence of dye constituents in the matrix of APC. It was evident that the chosen dyes adsorbed well on the porous surface of prepared APC.

The chemical elemental composition of APC was analyzed using Energy Dispersive Analysis X-Ray (EDAX). The EDAX spectra of composite confirmed the presence of $\mathrm{Al}, \mathrm{C}$, and $\mathrm{O}$ elements in the composite. It is also estimated that the composition of carbon (72\%) was very high, and the oxygen $(26 \%)$ and alumina (12\%) were in the ratio of $2: 1$, respectively.

3.2. Effect of $p H$ on Adsorption. Determination of the impact of $\mathrm{pH}$ is essential in the adsorption experiments. The adsorption of CR and SF dyes onto APC was investigated for different $\mathrm{pH}$ from 2 to 11 . The observed results are illustrated in Figure 4(a). The removal percentage of CR dye solution was plotted against the $\mathrm{pH}$ at $25 \mathrm{~mL}$ of $30 \mathrm{mg} / \mathrm{L}$ initial dye solution, $0.1 \mathrm{~g}$ APC dose, and $55^{\circ} \mathrm{C}$ for prefixed process time. As represented in Figure 4(a), the removal percentage of CR solution reduced from 98 to $36.8 \%$ when the solution $\mathrm{pH}$ was changed from 2 to 4 . At the acidic range, the percentage of dye removal for CR was higher initially and suddenly decreased with an increase in $\mathrm{pH}$, mostly in the first region. From this study, the optimum $\mathrm{pH}$ was determined as 2 at which the maximum $98 \%$ removal of CR dye was observed. With decreasing $\mathrm{pH}$, weak base groups were protonated and acquired a net positive charge on the APC surface. This brought out an electrostatic attraction between the surface of the APC and CR. As a result, a high removal percentage was observed.

SF has a pKa value of 6.4 and a pH 10. The SF removal percentage was witnessed in the basic $\mathrm{pH}$ range, whereas with a gradual decrease in $\mathrm{pH}$, it showed an indicative 


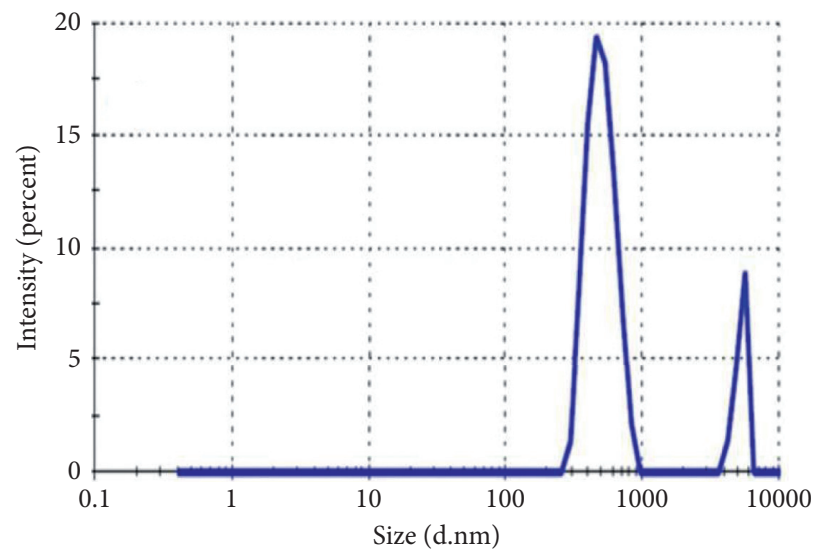

(a)

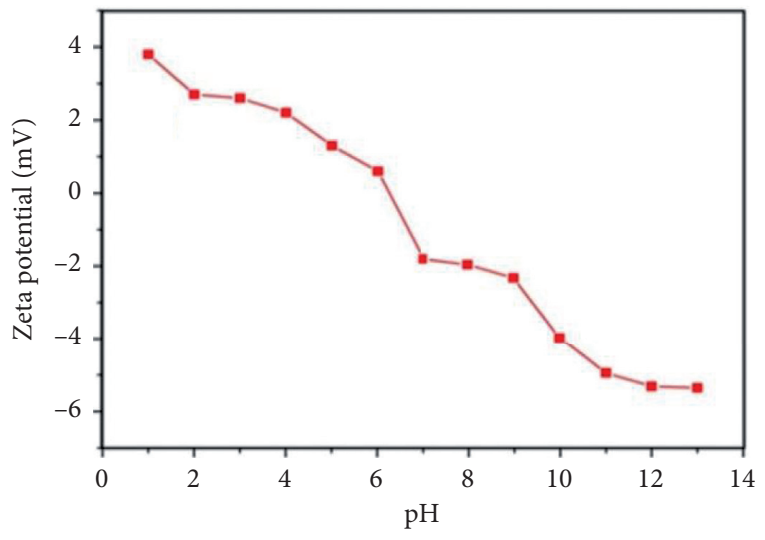

(b)

Figure 1: (a) The particle size distribution of APC after carbonization at $400^{\circ} \mathrm{C}$ for $120 \mathrm{~min}$. (b) Zeta Potential curve of APC.

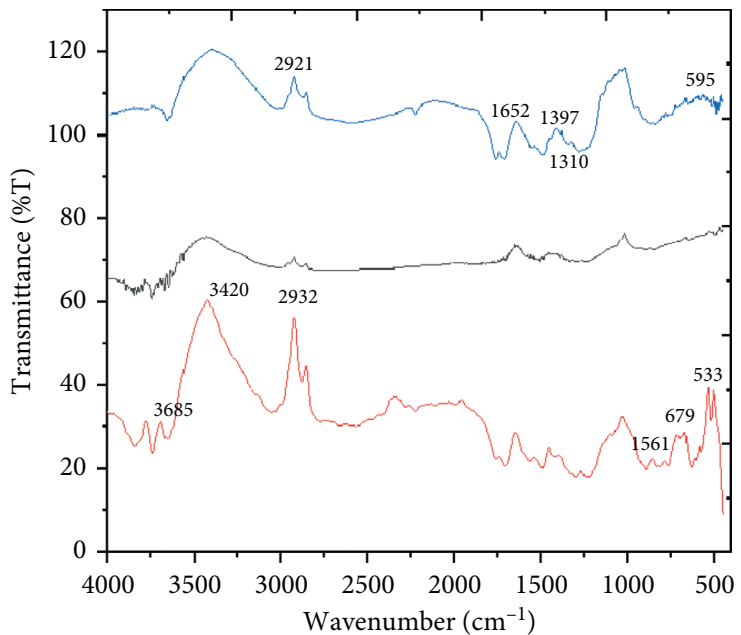

FIGURE 2: FTIR spectra of APC (a) before adsorption; (b) after CR adsorption; (c) after SF adsorption.

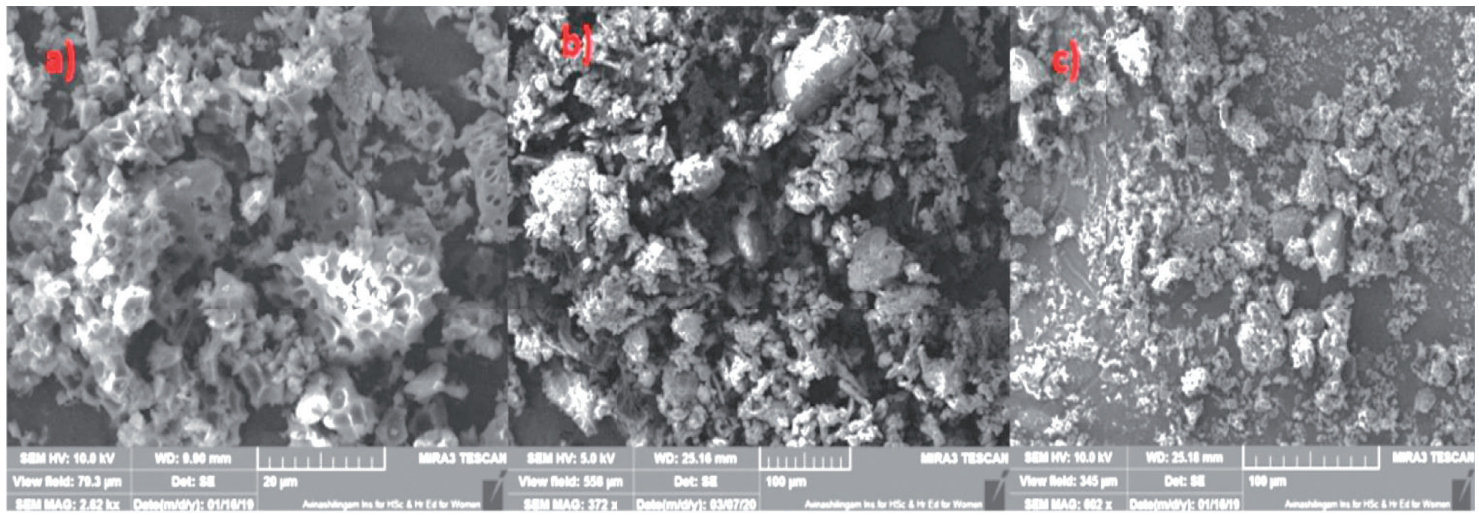

FIGURE 3: FESEM micrographs of APC (a) before adsorption; (b) after CR adsorption; (c) after SF adsorption.

reduction in the dye removal. The percentage removal of dye ranges from 35 to $64 \%$ removal when $\mathrm{pH}$ varied from 3 to 11 . The maximum removal of color was attained at $\mathrm{pH}$ 10.0, and the removal percentage of SF at this optimum $\mathrm{pH}$ was $64 \%$. At $\mathrm{pH} 10$, further investigation was carried out with a low $p k a$ value at $55^{\circ} \mathrm{C}$. As $\mathrm{SF}$ is a basic dye, a strong electrostatic repulsion exists between the positively charged ions present in the SF solution and 


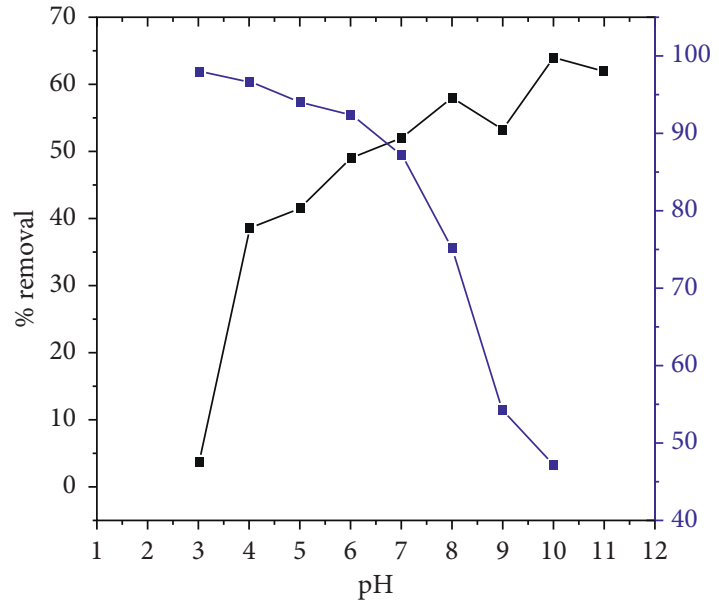

-1-SF

$-1-\mathrm{CR}$

(a)
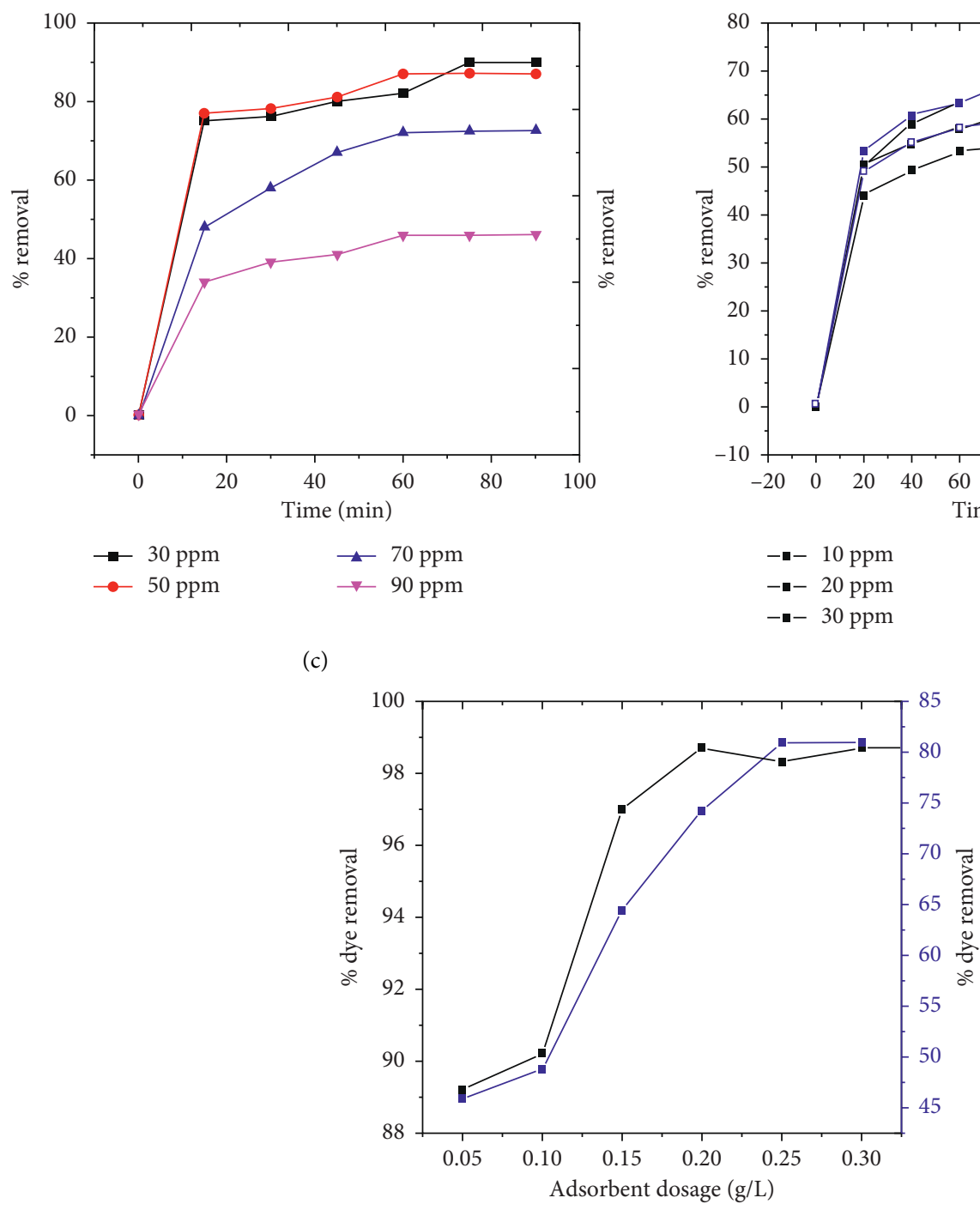

$-1-\mathrm{CR}$

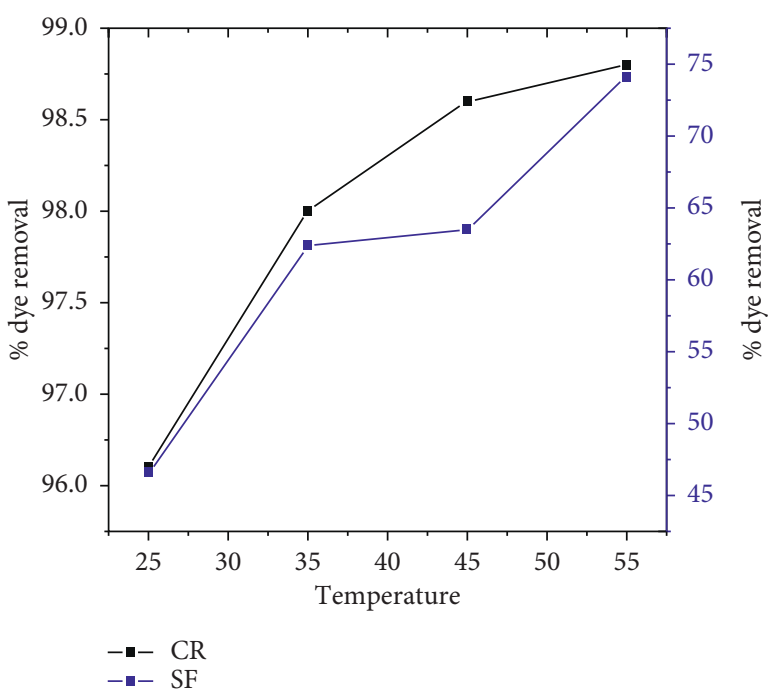

(b)

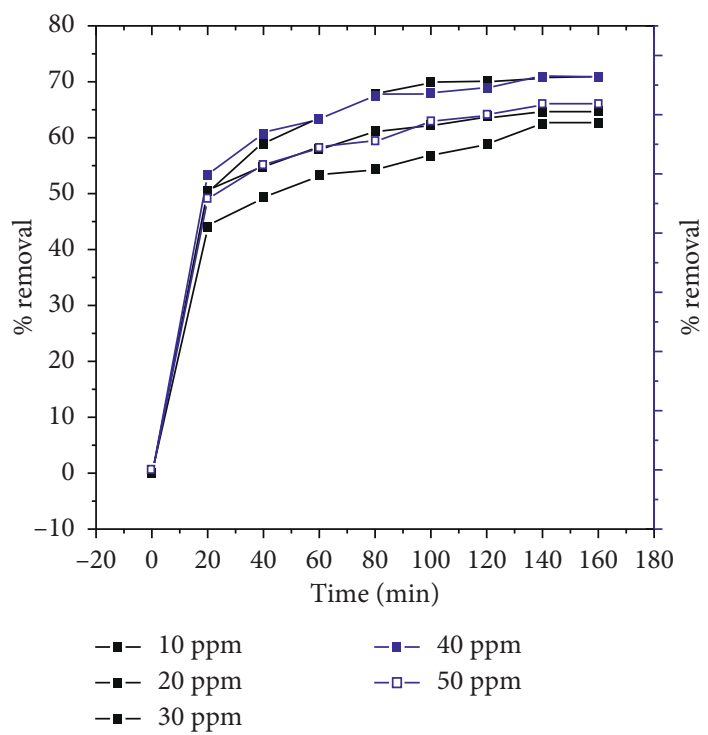

(d)

(e)

Figure 4: Effects of (a) pH; (b) temperature; (c) initial CR concentration; (d) initial SF concentration; (e) APC dosage. 
the positively charged APC surface due to the protonation of the functional groups, which resulted in low removal percentage. Also, with an increase in $\mathrm{pH}$ of the SF solution, a significant rate of dye removal was noted, as represented in Figure 4(a). At high $\mathrm{pH}$, consecutive deprotonation of the positively charged groups present on the surface of APC existed. It led to the strong electrostatic desirability between SF and APC.

3.3. Effect of Temperature on Adsorption. At four different temperatures $\left(25,35,45\right.$, and $\left.55^{\circ} \mathrm{C}\right)$, the experiments were carried out for adsorption of CR and SF onto the APC material. Figure 4(b) represents that increase in temperature resulted in the increased percentage of dye removal. It denoted that high temperature favored the CR and SF removal from aqueous solution. The solubility of dyes decreased when the temperature increased and hence, it led to a high adsorption rate-a similar result for the adsorption of dyes reported in the literature [5]. Due to the rise in the mobility of the dye molecules at high temperatures, there was an increase in dye adsorption. Therefore, the adsorptive uptake of CR and SF increased with an increase in temperature could partially be attributed to chemisorption.

\subsection{Effect of Initial Dye Concentrations and Contact Time.} The investigation about the influence of different initial dye concentrations of CR and SF by APC is represented in Figures 4(c) and 4(d). The active sites of the adsorbent were surrounded by much more CR and SF ions when the concentration of CR or SF solution was higher. The efficiency of the adsorption phenomenon was higher in CR than $\mathrm{SF}$. The removal percentage was higher for low dye concentration of $30 \mathrm{ppm}$ and $10 \mathrm{ppm}$ for CR and SF, respectively. The value of $q_{\mathrm{e}}$ increased when the initial CR and SF dye concentrations were increased. The removal percentage was improved with contact time and became constant at a particular time. So the value of $q_{\mathrm{em}}$ was raised with the augmentation of initial CR and SF dye concentrations. Otherwise, it could be seen that initial dye concentration increased when the percentage removal of dye decreased. At the minimum dye concentrations, entire dye molecules present in the reaction mixture interacted well to the binding sites of APC, enabling about 98\% for CR adsorption and 64\% for SF. However, all adsorbents were saturated at an absolute concentration and had a limited number of binding sites. There were more dye molecules persisting unabsorbed in the solution at higher concentrations. It might be a reason that the saturation of binding sites resulted in decreased adsorption efficiency. A similar outcome was observed for adsorption of CR and SF on alumina-nickel composites [40].

3.5. Effect of Adsorbent Dosage. The adsorbent dose is an essential parameter for the examination of adsorption studies, which determined the percentage removal of given initial dye concentration. For analyzing the impact of adsorbent dosage on the adsorption of $\mathrm{CR}$ and $\mathrm{SF}$ dyes, the adsorbent dose was varied from 0.05 to $0.3 \mathrm{~g} / \mathrm{L}$ at $55^{\circ} \mathrm{C}$ with optimized pH and time. The number of dye molecules adsorbed over APC by changing the dosage of APC is illustrated in Figure 4(e). It showed that the adsorption of CR and SF increased as the amount of adsorbent was increased from 0.2 to $0.3 \mathrm{~g} / \mathrm{L}$ for CR and 0.25 to $0.3 \mathrm{~g} / \mathrm{L}$ for SF and then maintained constant. This was due to the number of active sites increased on alumina polymer matrix with the increase in the adsorbent dosage to a certain level. Therefore, $0.2 \mathrm{~g} / \mathrm{L}$ and $0.25 \mathrm{~g} / \mathrm{L}$ of APC for CR and SF dye, respectively, were taken as the optimum adsorbent dose for further experiments.

\section{Adsorption Isotherm Studies}

Establishment of equilibrium correlation based on adsorption data is necessary for the optimization and design of adsorption process. To investigate the batch adsorption data Langmuir, Freudlich and Temkin isotherms were employed.

4.1. Langmuir Isotherm. Langmuir isotherm studies say that adsorption proceeds on monolayer surface and energy will be the same on the sites of adsorption. Adsorption isotherm provides valuable information such as equilibrium sorption capacity and certain constants whose values express the surface properties and affinity of the adsorbent. The linear equation of Langmuir isotherm is symbolized as in the following equation [41]:

$$
\frac{C_{\mathrm{e}}}{q_{\mathrm{e}}}=\frac{1}{q_{\mathrm{m}}} C_{\mathrm{e}}+\frac{1}{K_{\mathrm{L}} q_{\mathrm{m}}},
$$

where $q_{\mathrm{m}}$ is the maximum monolayer capacity $(\mathrm{mg} / \mathrm{g}) ; K_{\mathrm{L}}$ is the Langmuir isotherm constant $(\mathrm{L} / \mathrm{mg})$. The graph was plotted $C_{\mathrm{e}} / q_{\mathrm{e}}$ against $C_{\mathrm{e}}$ at various temperatures $(25,35,45$, and $55^{\circ} \mathrm{C}$ ) in Figures 5(a) and 5(b) from which $q_{\mathrm{m}}$ and $K_{\mathrm{L}}$ values were calculated. From Table 1 for CR dye, $q_{\mathrm{m}}$ and $K_{\mathrm{L}}$ values increased with an increase in temperature till $45^{\circ} \mathrm{C}$ and then an insignificant increment was noticed. The estimated correlation coefficients value $\left(R^{2}\right)$ ranges from 0.917 to 0.994 . For SF dye, the $q_{\mathrm{m}}$ value decreased and $K_{\mathrm{L}}$ value increased with an increase in temperature, and the $R^{2}$ was determined in ranges from 0.890 to 0.932 . It was confirmed from the value of $R^{2}$ that both adsorption data measured for CR and SF onto APC reasonably fitted with the Langmuir isotherm. A similar isotherm response was found for the adsorption of $\mathrm{Pb}(\mathrm{II}), \mathrm{Zn}(\mathrm{II})$, and $\mathrm{Cd}(\mathrm{II})$ on hyacinth weed [42].

4.2. Freundlich Isotherm. Freundlich isotherm studies reveal that the adsorption takes place on the heterogeneous surface and the energy of adsorption will be non-uniform [39]. The linear equation of Freundlich isotherm can be denoted as the following equation [43]:

$$
\log q_{\mathrm{e}}=\log K_{\mathrm{f}}+\frac{1}{n} \log C_{\mathrm{e}}
$$

where $K_{\mathrm{f}}$ is the Freundlich isotherm constant $(\mathrm{mg} / \mathrm{g})$ and $n$ is the adsorption intensity. The measured values of both $\mathrm{CR}$ and SF dyes for Freundlich isotherm are presented in 


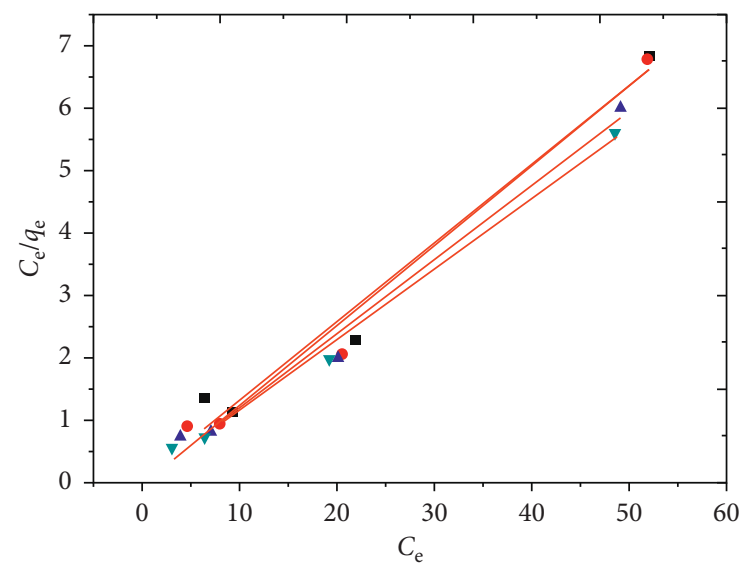

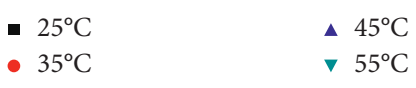

(a)

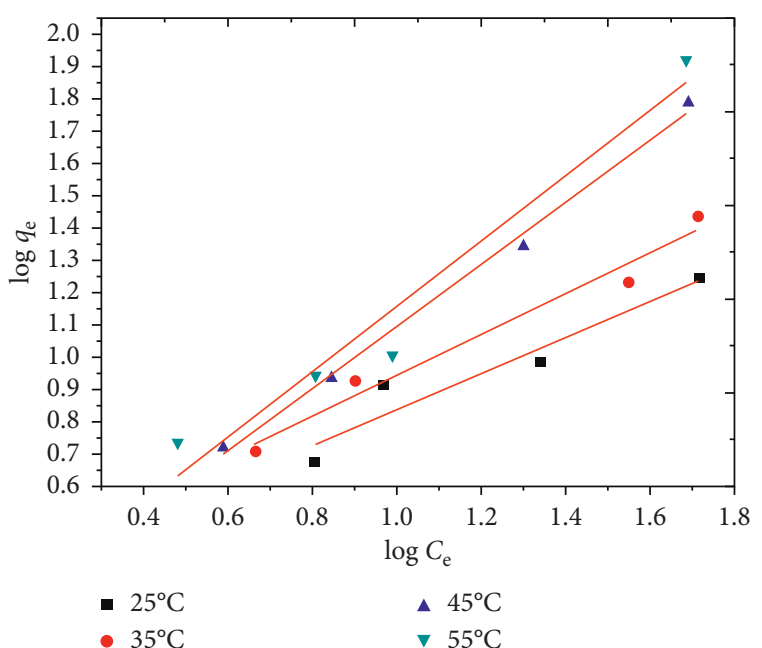

(c)

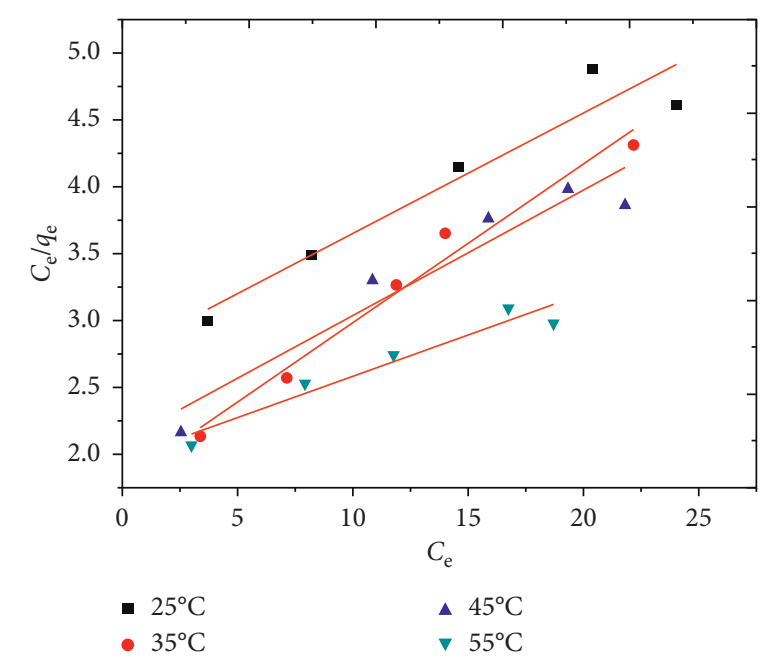

(b)

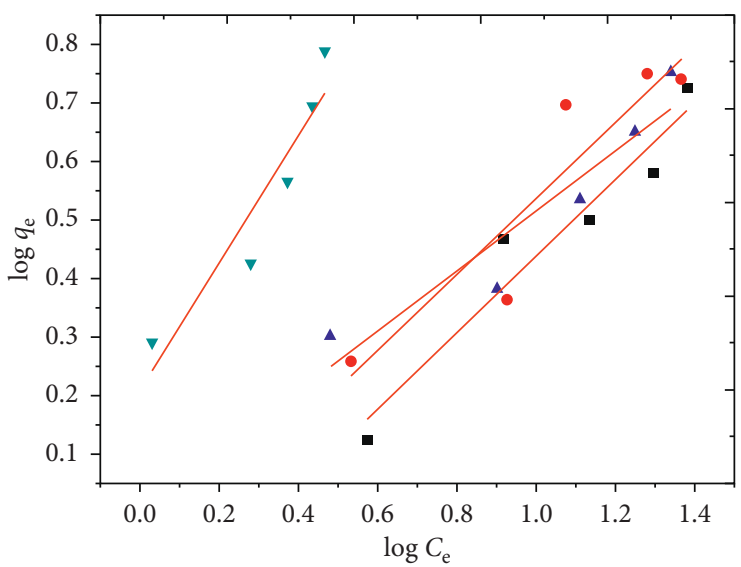

- $25^{\circ} \mathrm{C}$

- $35^{\circ} \mathrm{C}$

- $45^{\circ} \mathrm{C}$

จ $55^{\circ} \mathrm{C}$

(d)

FIGURE 5: Langmuir isotherm at various temperatures of (a) CR and (b) SF; Freundlich isotherm at various temperatures of (a) CR and (b) SF.

TABLE 1: Isotherm constants.

\begin{tabular}{|c|c|c|c|c|c|c|c|c|c|}
\hline \multirow{2}{*}{$\mathrm{T}\left({ }^{\circ} \mathrm{C}\right)$} & \multicolumn{3}{|c|}{ Langmuir } & \multicolumn{3}{|c|}{ Freundlich } & \multicolumn{3}{|c|}{ Temkin } \\
\hline & $q_{\mathrm{m}}(\mathrm{mg} / \mathrm{g})$ & $K_{1}(\mathrm{~L} / \mathrm{mg})$ & $R^{2}$ & $K_{\mathrm{f}}(\mathrm{L} / \mathrm{g})$ & $n_{\mathrm{f}}$ & $R^{2}$ & $b_{\mathrm{T}}$ & $A_{\mathrm{T}}$ & $R^{2}$ \\
\hline \multicolumn{10}{|l|}{ CR dye } \\
\hline 25 & 7.812 & 1.702 & 0.917 & 1.135 & 0.987 & 0.972 & 6254.56 & 1.199 & 0.735 \\
\hline 35 & 7.936 & 2.56 & 0.975 & 1.154 & 1.037 & 0.981 & 6265.05 & 0.161 & 0.776 \\
\hline 45 & 8.403 & 2.975 & 0.984 & 1.328 & 1.605 & 0.986 & 6417.82 & 0.074 & 0.827 \\
\hline 55 & 8.928 & 3.294 & 0.958 & 1.362 & 1.808 & 0.994 & 7417.88 & 0.034 & 0.923 \\
\hline \multicolumn{10}{|l|}{ SF dye } \\
\hline 25 & 2.571 & 0.380 & 0.932 & 0.726 & 0.077 & 0.927 & 1092.245 & 0.5431 & 0.945 \\
\hline 35 & 3.172 & 0.507 & 0.857 & 0.729 & 1.264 & 0.979 & 1098.70 & 0.5184 & 0.752 \\
\hline 45 & 3.547 & 0.517 & 0.890 & 0.811 & 1.358 & 0.919 & 1279.076 & 0.4924 & 0.896 \\
\hline 55 & 6.534 & 0.972 & 0.890 & 1.080 & 1.449 & 0.935 & 1318.629 & 0.4391 & 0.937 \\
\hline
\end{tabular}

Figures 5(c) and 5(d). The graph was plotted as $\log q_{\mathrm{e}}$ against $\log C_{\mathrm{e}}$ at different temperatures $\left(25,35,45\right.$, and $\left.55^{\circ} \mathrm{C}\right)$. From this graph, $n$ and $K_{\mathrm{f}}$ values were calculated. For CR, $n$ and $K_{\mathrm{f}}$ values decreased with an increase in temperature and $R^{2}$ values range from 0.971 to 0.994 , as presented in Table 1 . In the case of SF dye, these values increased with an increase in temperature and $R^{2}$ values range from 0.927 to $0.935 . R^{2}$ indicated that the attained adsorption data of CR dye onto 
APC fitted with the Freundlich isotherm rather than the Langmuir isotherm. The estimated adsorption data of SF onto APC was also fitting good with Freundlich isotherm. Similar isotherm results were also reported in reactive dyes removal using biomaterial-based polymer composites [44].

4.3. Temkin Isotherm. The Temkin equation reveals that the heat of adsorption weakens with the increase in the area of surface coverage. The linear equation for Temkin isotherm can be represented as the following equation:

$$
q_{\mathrm{e}}=B \ln A_{\mathrm{T}}+B \ln C_{\mathrm{e}},
$$

where $A_{\mathrm{T}}$ is the Temkin isotherm equilibrium binding constant $(\mathrm{L} / \mathrm{g}), B_{\mathrm{T}}$ is the Temkin isotherm constant, $R$ is the universal gas constant $(8.314 \mathrm{~J} / \mathrm{mol} / \mathrm{K}), T$ is the temperature at $298 \mathrm{~K}$, and $B$ is the constant related to the heat of adsorption $(\mathrm{J} / \mathrm{mol})$. The graph was plotted between $q_{\mathrm{e}}$ against $\ln C_{\mathrm{e}}$ at different temperatures $\left(25,35,45\right.$, and $\left.55^{\circ} \mathrm{C}\right)$ in Figures 6(a) and 6(b) from which $B_{\mathrm{T}}$ and $A_{\mathrm{T}}$ values were calculated. From Table 1, for CR, $B_{\mathrm{T}}$ and $A_{\mathrm{T}}$ values decreased with an increase in temperature and $R^{2}$ values ranged from 0.735 to 0.923 . In the case of $\mathrm{SF}, B_{\mathrm{T}}$ and $A_{\mathrm{T}}$ values decreased with an increase in temperature and values ranged from 0.752 to 0.945 . The values of $R^{2}$ indicated that the adsorption data of CR and SF dyes onto APC were not well fitted into Temkin isotherm like Freundlich isotherm. Similar isotherm results were also reported in adsorption of Congo red dye from aqueous solutions using the roots of Eichhornia crassipes [45].

\section{Adsorption Kinetics}

The uptake of CR and SF onto APC at temperatures extending from 25 to $55^{\circ} \mathrm{C}$ and its diffusion processes were studied at an initial CR concentration of $30 \mathrm{mg} / \mathrm{L}$ and $\mathrm{SF}$ concentration of $10 \mathrm{mg} / \mathrm{L}$ for the same range of temperature, $\mathrm{pH} 2$ and 10 for CR and SF, respectively. The experimental data was investigated with five kinetic models: pseudo-firstorder, pseudo-second-order, Bhangam kinetic model, intraparticle diffusion, and Elovich model.

5.1. Pseudo-First-Order Kinetic Model. The pseudo-firstorder kinetic model is more suitable for lower concentrations of solute. The pseudo-first-order kinetic model equation is expressed by the following equation [46]:

$$
\log \left(q_{\mathrm{e}}-q_{\mathrm{t}}\right)=\log q_{\mathrm{e}}-\left(\frac{K_{1}}{2.303}\right) t
$$

where $K_{1}$ is the rate constant of first-order adsorption $\left(\mathrm{min}^{-1}\right)$. The straight-line plot of $\log \left(q_{\mathrm{e}}-q_{\mathrm{t}}\right)$ against $t$ is given in Figures $7(\mathrm{a})$ and $7(\mathrm{~b})$ which indicates $\log \left(q_{\mathrm{e}}\right)$ as slope and intercept equal to $K_{1} / 2.303$. The amount of solute adsorbed per $g$ of APC at equilibrium $\left(q_{\mathrm{e}}\right)$ and the first-order rate constant $\left(K_{1}\right)$ could be evaluated from the slope and the intercept and the values are tabulated in Table 2. From the graph, the dye adsorption by APC did not obey the pseudofirst-order kinetics for both CR and SF. Similar outcome was observed in iron-doped phenolic resin-based activated carbon of micro- and nanoparticles for arsenic removal [47].

5.2. Pseudo-Second-Order Kinetics. The pseudo-second-order model developed on the assumption of chemisorption which involves valence and electrostatic forces via sharing of electrons between the dye and the adsorbent. This is given by the following equation [48]:

$$
\frac{t}{q_{\mathrm{t}}}=\frac{1}{k_{2} q_{\mathrm{e}}^{2}}+\left(\frac{1}{q_{\mathrm{e}}}\right) t,
$$

where $k_{2}$ is the rate constant. The plot of $\left(t / q_{\mathrm{t}}\right)$ versus time gives the plot for the pseudo-second-order model. Table 2 presents the value of $k_{2}$ and $q_{\mathrm{e}}$ for CR and SF dye adsorption at four different temperatures. From Table 2 and Figures 7(c) and $7(d)$, the pseudo-second-order equation fitted well with the experimental data, as the correlation coefficient $\left(R^{2}\right)$ was close to unity and extremely high $R^{2}$ was obtained for both $\mathrm{CR}$ and SF adsorption process compared with the first-order equation. As the experimental data fitted well with the pseudo-second-order model, the adsorption process was solely dependent on both APC and dyes concentration. This adsorption mechanism was chemically rate controlled. Similar kinetic results were obtained for basic dyes removal from aqueous solutions onto apricot stone activated carbon [49].

5.3. Bhangam Kinetic Model. Bhangam's model is a pore distribution model that can determine the rate-controlling step in the adsorption process, which is given by the following equation:

$$
\log q_{\mathrm{t}}=\log k C_{0}+\frac{1}{m} \log t
$$

The plot of $\log q_{\mathrm{t}}$ versus $\log t$ represents the Bhangam kinetic model. The graph was plotted for an initial dye concentration of $30 \mathrm{mg} / \mathrm{L}$ and $10 \mathrm{mg} / \mathrm{L}$ for CR and SF, respectively, as shown in Figures 8(a) and 8(b). The correlation coefficients $\left(R^{2}\right)$ obtained ranged from 0.811 to 0.976 for CR and SF, respectively, as shown in Table 2. Nonlinear curve was obtained for CR but a linear curve resulted in the case of $\mathrm{SF}$ adsorption. This indicated that the rate-limiting step was the adsorbate diffusion into pore or matrix for CR. Similar kinetics observed for the adsorption of CR and SF onto kenaf core fiber [46].

5.4. Intraparticle Diffusion Model. Transport of dye molecules from the bulk of the solution into the adsorbent is normally via an intraparticle diffusion, which is regularly the rate-limiting step in the adsorption process. Intraparticle diffusion model, according to which the amount adsorbed at time $t, q_{\mathrm{t}}$, reads as follows:

$$
q_{\mathrm{t}}=k_{p} t^{0.5}+c
$$

where $k_{\mathrm{p}}$ is the intraparticle diffusion rate constant (mg $\left.\mathrm{g}^{-1} \min ^{0.5}\right), C\left(\mathrm{mg} \mathrm{g}^{-1}\right)$ is a constant related to the thickness 


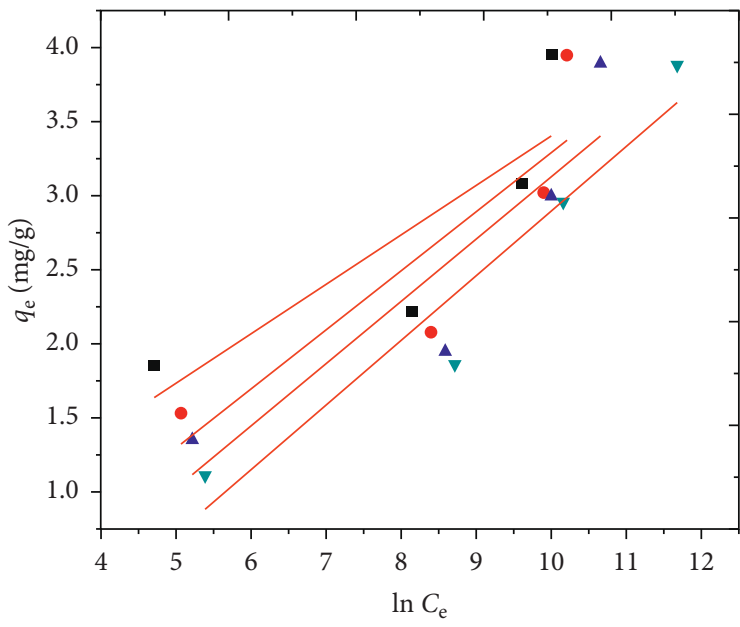

- $25^{\circ} \mathrm{C}$

- $35^{\circ} \mathrm{C}$
- $45^{\circ} \mathrm{C}$

จ $55^{\circ} \mathrm{C}$

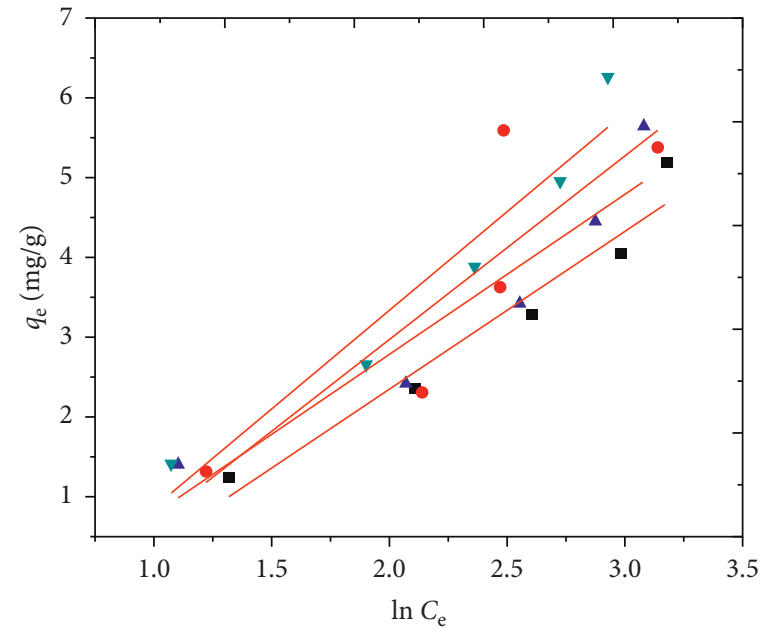

- $25^{\circ} \mathrm{C}$

- $35^{\circ} \mathrm{C}$
- $45^{\circ} \mathrm{C}$

จ $55^{\circ} \mathrm{C}$

(b)

FiguRE 6: Temkin isotherm of (a) CR; (b) adsorption of SF at various temperatures.
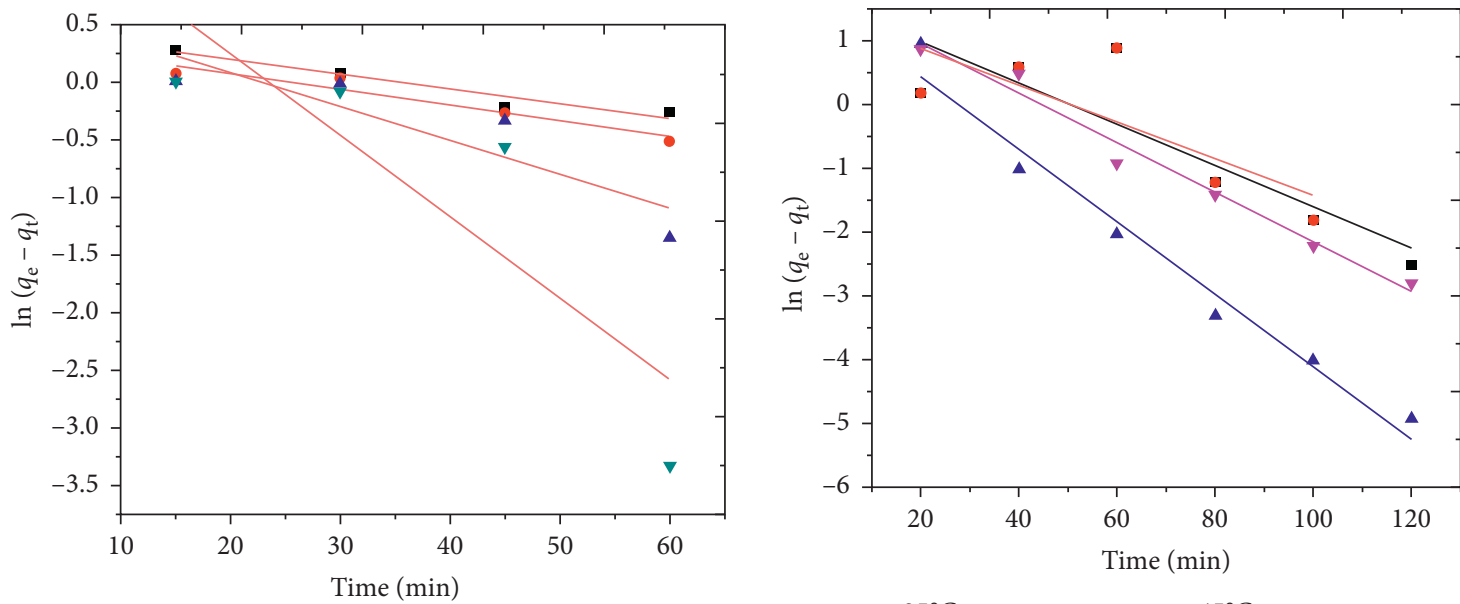

- $25^{\circ} \mathrm{C}$

- $45^{\circ} \mathrm{C}$

- $35^{\circ} \mathrm{C}$

> $55^{\circ} \mathrm{C}$

- $25^{\circ} \mathrm{C}$

- $45^{\circ} \mathrm{C}$

- $35^{\circ} \mathrm{C}$

จ $55^{\circ} \mathrm{C}$

(a)



- $25^{\circ} \mathrm{C}$

- $45^{\circ} \mathrm{C}$

- $35^{\circ} \mathrm{C}$

จ $55^{\circ} \mathrm{C}$

- $25^{\circ} \mathrm{C}$

- $35^{\circ} \mathrm{C}$

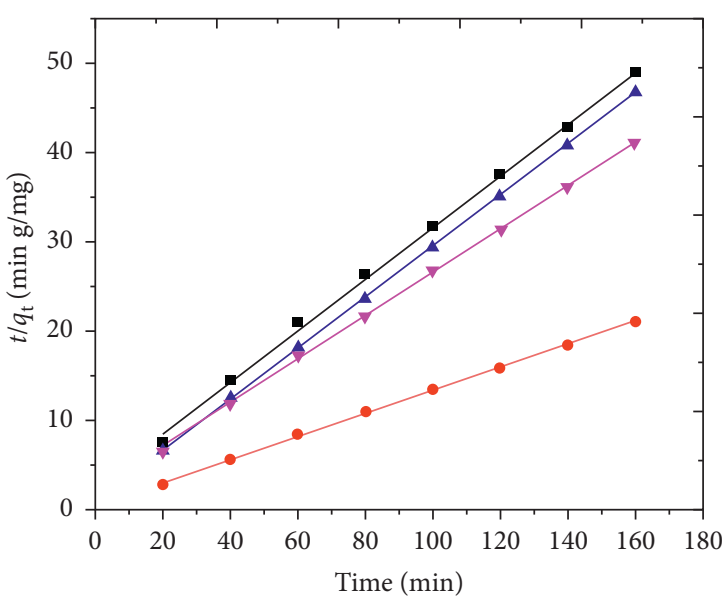

(c)

(d)

Figure 7: Pseudo-first-order kinetics of (a) CR and (c) SF; pseudo-second-order kinetics of (b) CR and (d) SF. 
TABLE 2: Kinetic constants for adsorption studies.

\begin{tabular}{|c|c|c|c|c|c|c|c|c|c|c|c|c|c|c|c|}
\hline \multirow[b]{2}{*}{$\mathrm{T}\left({ }^{\circ} \mathrm{C}\right)$} & \multicolumn{3}{|c|}{ Pseudo-first-order } & \multicolumn{3}{|c|}{ Pseudo-second-order } & \multicolumn{3}{|c|}{ Intraparticle diffusion } & \multicolumn{3}{|c|}{ Bangham } & \multicolumn{3}{|c|}{ Elovich } \\
\hline & $\begin{array}{c}K_{1} \\
\left(\mathrm{Lg}^{-1} \min ^{-1}\right)\end{array}$ & $\begin{array}{c}q_{\mathrm{e}} \\
\left(\mathrm{mg} \mathrm{g}^{-1}\right)\end{array}$ & $R^{2}$ & $\begin{array}{c}K_{2} \\
\left(\operatorname{gmin}^{-1} \mathrm{~L}^{-1}\right)\end{array}$ & $\begin{array}{c}q_{\mathrm{e}} \\
\left(\mathrm{mgg}^{-1}\right)\end{array}$ & $R^{2}$ & $\begin{array}{c}K_{\mathrm{p}} \\
\left(\mathrm{mg} \mathrm{g}^{-1} \min ^{-0.5}\right)\end{array}$ & $\mathrm{C}$ & $R^{2}$ & $\begin{array}{c}K_{\mathrm{r}} \\
\left(\mathrm{mgg}^{-1} \min ^{-1}\right)\end{array}$ & M & $R^{2}$ & $\begin{array}{c}\alpha \\
\left(\mathrm{mg} \mathrm{g}^{-1} \min ^{-1}\right)\end{array}$ & B & $R^{2}$ \\
\hline \multicolumn{16}{|l|}{ CR Dye } \\
\hline 25 & 0.156 & 1.421 & 0.933 & 0.026 & 8.130 & 0.991 & 0.211 & 5.180 & 0.886 & 1.93 & 12.19 & 0.843 & 157.24 & 1.572 & 0.825 \\
\hline 35 & 0.066 & 1.558 & 0.928 & 0.024 & 8.196 & 0.994 & 0.214 & 5.740 & 0.880 & 2.036 & 12.50 & 0.811 & 1222.4 & 1.540 & 0.804 \\
\hline 45 & 0.029 & 1.569 & 0.790 & 0.022 & 8.928 & 0.997 & 0.217 & 6.517 & 0.906 & 2.15 & 11.36 & 0.844 & 3321.5 & 1.485 & 0.844 \\
\hline 55 & 0.027 & 1.958 & 0.799 & 0.017 & 9.174 & 0.998 & 0.250 & 6.770 & 0.901 & 2.185 & 9.17 & 0.878 & 3330 & 1.319 & 0.875 \\
\hline \multicolumn{16}{|l|}{ SF Dye } \\
\hline 25 & 0.092 & 0.785 & 0.881 & 0.076 & 3.521 & 0.878 & 0.051 & 2.206 & 0.969 & 1.289 & 18.18 & 0.953 & 25.929 & 4.672 & 0.946 \\
\hline 35 & 0.062 & 1.150 & 0.927 & 0.028 & 4.115 & 0.999 & 0.088 & 2.659 & 0.965 & 1.386 & 15.38 & 0.948 & 31.186 & 2.865 & 0.946 \\
\hline 45 & 0.041 & 1.196 & 0.983 & 0.026 & 4.310 & 0.999 & 0.101 & 2.845 & 0.876 & 1.485 & 8.47 & 0.951 & 45.451 & 2.469 & 0.949 \\
\hline 55 & 0.039 & 1.740 & 0.968 & 0.005 & 7.812 & 0.999 & 0.102 & 6.339 & 0.934 & 2.129 & 8.33 & 0.976 & 108.41 & 2.415 & 0.978 \\
\hline
\end{tabular}

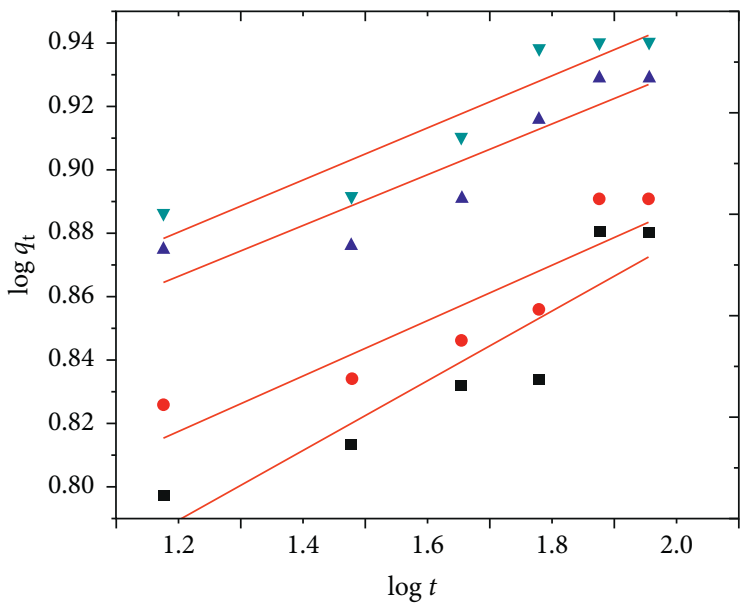

- $25^{\circ} \mathrm{C}$

- $35^{\circ} \mathrm{C}$

- $45^{\circ} \mathrm{C}$

จ $55^{\circ} \mathrm{C}$

(a)

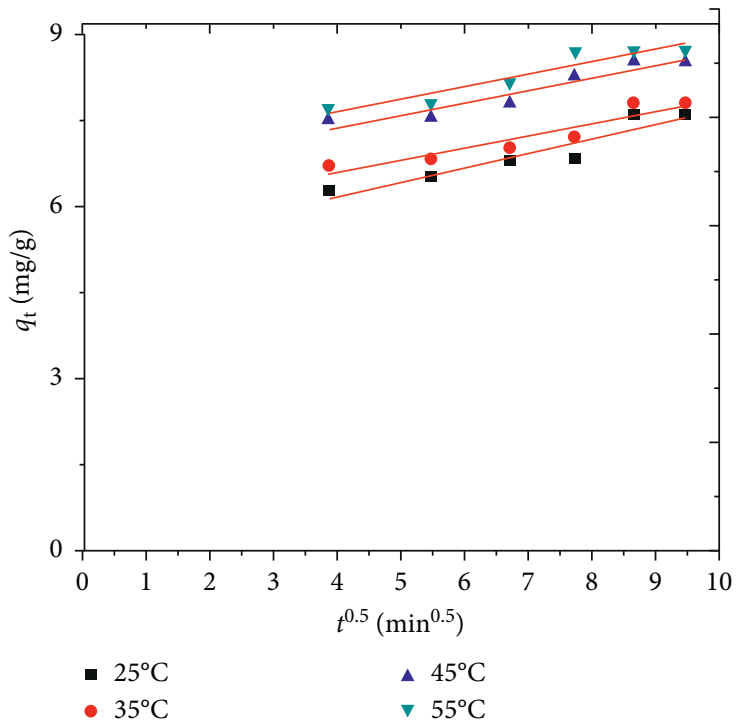

(c)

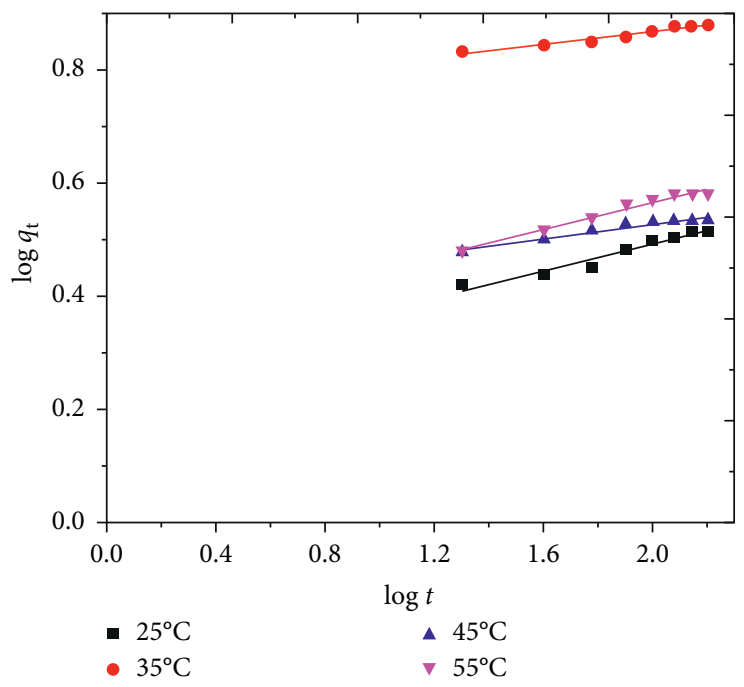

(b)

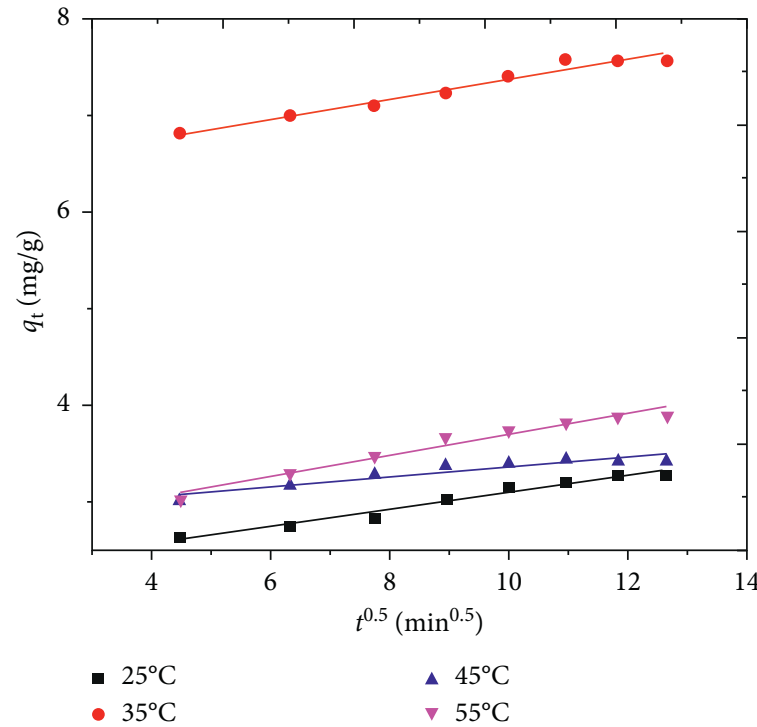

(d)

FIGURE 8: Bhangam kinetics of (a) CR and (b) SF; intraparticle diffusion kinetics of (c) CR and (d) SF. 


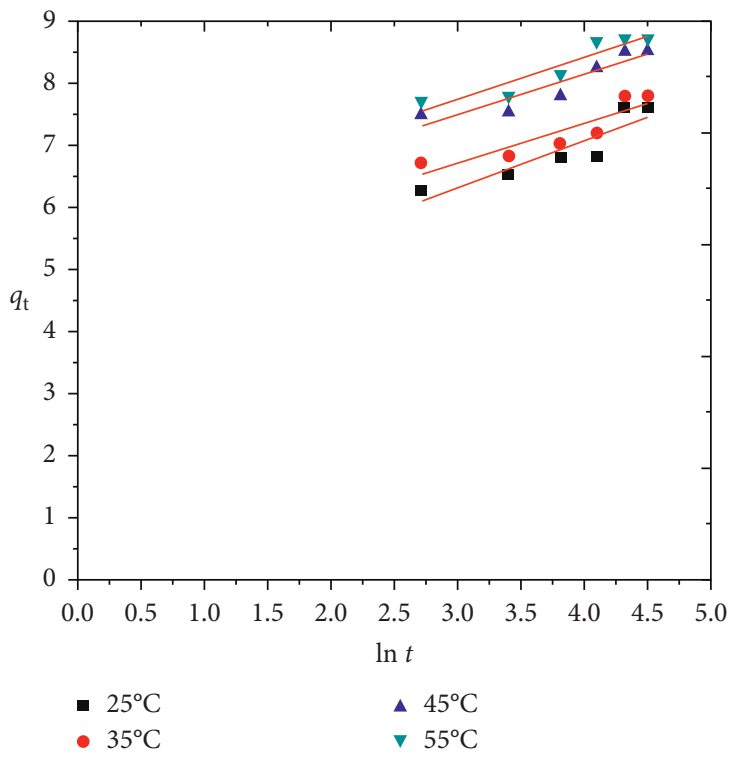

(a)

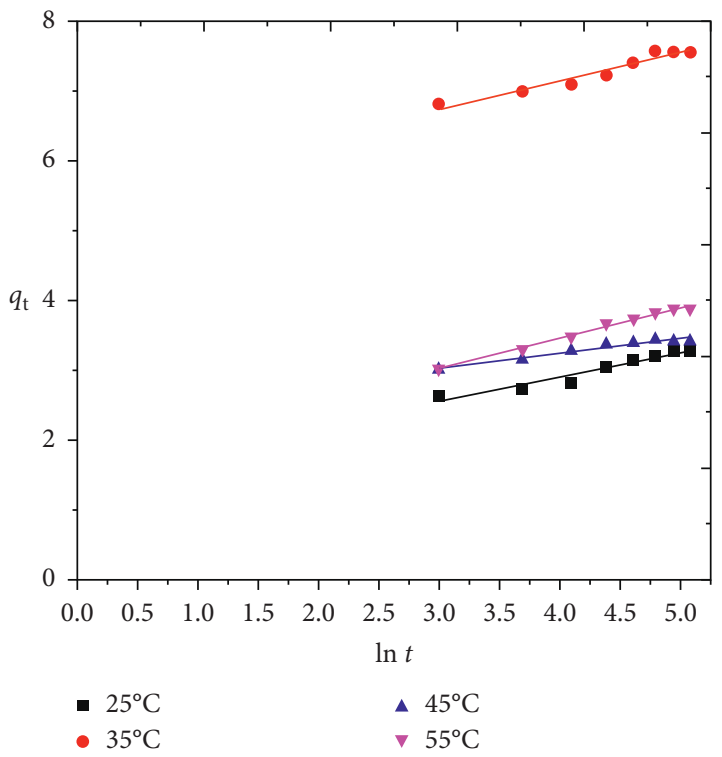

(b)

FIgURE 9: Elovich adsorption kinetics of (a) CR and (b) SF onto APC.

TABLE 3: Thermodynamics parameters of CR and SF Dyes on APC.

\begin{tabular}{lccc}
\hline Temperature $(\mathrm{K})$ & $\Delta G^{\circ}(\mathrm{KJ})$ & $\Delta H^{\circ}(\mathrm{KJ})$ & $\Delta S^{\circ}(\mathrm{KJ} / \mathrm{k})$ \\
\hline CR dye & & & \\
298 & -3.33 & 42.52 & 123.76 \\
308 & -5.50 & & \\
318 & -8.639 & & \\
328 & -9.776 & & \\
\hline SF dye & & & \\
298 & -2.42 & 31.65 & \\
308 & -3.26 & & \\
318 & -5.61 & & \\
328 & -7.14 & & \\
\hline
\end{tabular}

of the boundary layer. The graph plotted between $q_{t}$ versus $t^{0.5}$ provided a straight line, as presented in Figures $8(\mathrm{c})$ and $8(\mathrm{~d})$. From the graph, $k_{\mathrm{p}}$ and $C$ was determined from the slope and intercept. Values of $C$ indicated the thickness of the boundary layer; i.e., the larger intercept, the greater the boundary layer effect. The small value of the intraparticle diffusion constant indicated that the boundary layer has a less significant effect on the diffusion and is shown in Table 2. A similar result was reported for basic dyes adsorption onto activated carbon [50].

5.5. Elovich Model. Elovich equation is also used to describe second-order kinetic assuming that the actual solid adsorbent surfaces are energetically heterogeneous. The Elovich equation is given as follows:

$$
\frac{\mathrm{d} q}{\mathrm{~d} t}=\alpha \exp \left(-\beta q_{\mathrm{t}}\right)
$$

This simplified equation (11) is as follows:

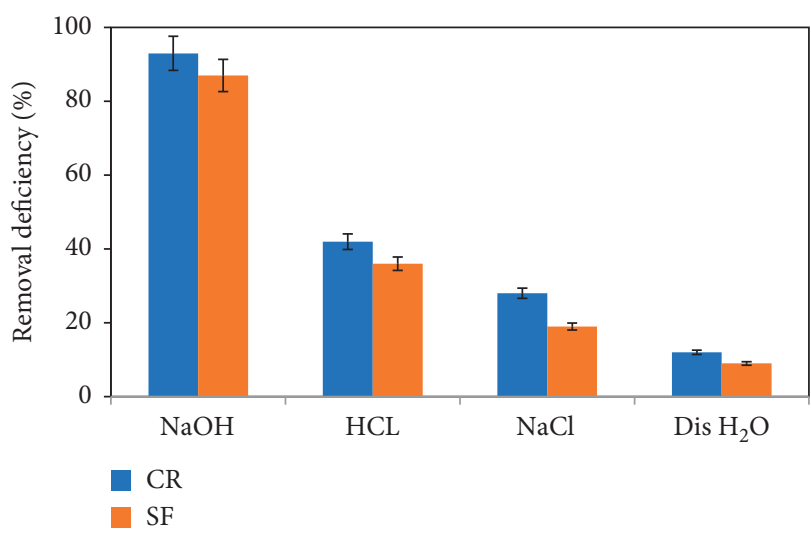

FIGURE 10: Desorption studies of CR and SF dyes adsorbed on APC adsorbent.

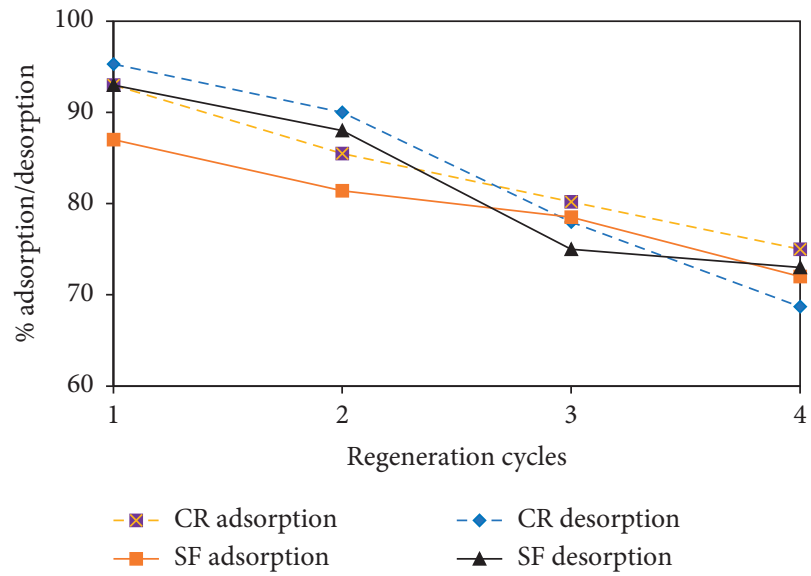

FIgURE 11: Regeneration cycles of CR and SF dyes on APC. 
TABLE 4: Adsorption capacities of various adsorbents onto SF and CR dyes.

\begin{tabular}{lcc}
\hline Adsorbents & Adsorption capacity $(\mathrm{mg} / \mathrm{g})$ & Reference \\
\hline CR dye & & \\
Eichhornia crassipes & 1.58 & {$[45]$} \\
Activated carbon from coir pith & 6.72 & {$[13]$} \\
Activated carbon (laboratory grade) & 1.88 & {$[51]$} \\
Cashew nutshell & 5.18 & {$[54]$} \\
Kaolin (clay materials) & 5.44 & {$[55]$} \\
Zeolite & 3.03 & {$[55]$} \\
Nabentonite & 7.29 & {$[55]$} \\
APC & 8.928 & Present study \\
SF dye & & \\
Activated carbon derived from coconut shell & 0.9980 & {$[56]$} \\
Activated carbon derived from pineapple peel & 1.0020 & {$[56]$} \\
Activated carbon & 3.183 & {$[9]$} \\
Activated rice husk & 0.2117 & {$[9]$} \\
Bambusa tulda & 32.26 & {$[57]$} \\
Tea waste & 29.49 & {$[53]$} \\
NaOH-treated rice husk & 37.97 & Present study \\
Fe-GAC & 26.55 & 6.534 \\
APC & & \\
\hline
\end{tabular}

$$
q_{t}=\beta \ln (\alpha \beta)+\beta \ln t q_{t} .
$$

Elovich constants $\alpha$ and $\beta$ were calculated from the plot of $q_{\mathrm{e}}$ versus $\ln (t)$, as shown in Figures 9(a) and 9(b). The correlation coefficient $\left(R^{2}\right)$ ranged from 0.804 to 0.875 for CR and from 0.946 to 0.978 for SF as shown in Table 2. $\alpha$ value increased for both $\mathrm{CR}$ and $\mathrm{SF}$ as temperature increased. Similar kinetic results were reported for acid dye removal by dead fungal biomass of $T$. harzianum [51]. This model fitted well for SF adsorption than the CR. It was concluded that SF followed chemisorption as it fitted well with the Elovich model. A similar kinetic result of the adsorption process was reported in the adsorption of dye by chitosan systems [52].

5.6. Adsorption Thermodynamics. The process of spontaneity approval is based on the thermodynamic study of the adsorption process. The study of adsorption thermodynamics was used to interpret the adsorption mechanism, either physical or chemical. For the adsorption of CR and SF, the thermodynamic parameters $\left(\Delta G^{\circ}, \Delta H^{\circ}, \Delta S^{\circ}\right)$ were determined using the Van't Hoff equation. The relationship between the parameters is given as follows:

$$
\Delta G^{\circ}=\Delta H^{\circ}-T \Delta S^{\circ} .
$$

Van't Hoff equation is obtained as follows:

$$
\ln K_{\mathrm{C}}=\frac{-\Delta H^{\circ}}{\mathrm{RT}}+\frac{\Delta S^{\circ}}{R},
$$

where $\mathrm{K}_{\mathrm{C}}$ is the equilibrium constant (dimensionless). The change in enthalpy $\left(\Delta H^{\circ}\right)$ and the change in entropy $\left(\Delta S^{\circ}\right)$ were determined from the slope and intercept of equation (11), respectively. Gibbs energy change was determined directly from equation (10). Table 3 lists the value of thermodynamic parameters for both CR and SF at four different temperatures, respectively. The negative value of $\Delta G$ at all experimented temperatures concluded that the adsorption process occurred spontaneously. In contrast, the positive value of $\Delta H^{\circ}$ indicated that the adsorption had occurred in an endothermic manner. As well as the positive value of $\Delta S^{\circ}$ suggested the arrangement of dye molecules onto APC very well with more randomness as temperature increased from 25 to $55^{\circ} \mathrm{C}$. Here, as temperature increased, the equilibrium constant also increased. This proved that the rate of adsorption increased with an increase in temperature. The value of entropy and enthalpy for the adsorption of CR and SF indicated the endothermic nature of the adsorption process. An endothermic reaction is generally associated with chemisorption [53].

5.7. Regeneration and Comparison with Other Adsorbents. The comparison of desorption efficiency is presented in Figure 10. The physical adsorption was not a predominant factor, while sodium hydroxide, which conformed high desorption efficiency $93 \%$ for CR and $87 \%$ SF representing the chemical binding of dye adsorbent of interface route. Apart from the other solvent such as $\mathrm{HCl}$ and $\mathrm{NaCl}$ of $\mathrm{H}^{+}$ and $\mathrm{Cl}^{-}$was obtained and neutralized in the distilled water, which was approved by the chemisorption of the dye molecules. APC was regenerated after CR and SF dyes adsorption several times and used for readsorption experiments. Regenerated APC was found good at least for 4 cycles (Figure 11).

The comparison of adsorption capabilities of various adsorbents for CR and SF dyes is presented in Table 4. It is clear from Table 4 that the prepared APC was moderately good compared with other adsorbents for CR and SF.

\section{Conclusion}

The adsorbent Alumina doped synthetic polymeric composite was synthesized by ball milling method. A yield of $81.5 \%$ was obtained by this method. Here, it was used to 
remove synthetic dyes such as CR and SF. Characterizations such as particle size distribution, zeta potential, BET, FTIR, and FESEM with EDAX were performed for the APC composite to study the nature of the synthesized particle. The particle size analysis of the synthetic polymeric composite estimated was about $503.7 \mathrm{~nm}$. FTIR study revealed that the presence of functional groups in the composite before and after adsorption process. FE SEM and EDAX characterization was done, which gave the surface image and the composition of the composite. A comparison of anionic and cationic dye using APC was studied. The effect of parameters for the adsorption process such as the effect of $\mathrm{pH}$, temperature, adsorbent dosage, initial dye concentration, and contact time for CR and SF adsorption were studied. A significant interaction was observed in CR and SF removal with the combination of parameters. The maximum adsorption of CR and SF dyes was obtained with $\mathrm{pH} 2$ and 10, respectively, at the process temperature of $55^{\circ} \mathrm{C}$. Several isotherm models were used to fit the experimental data point. The Langmuir isotherm, Freundlich isotherm, and Temkin isotherm were studied. Among them, observed experimental data were well fitted with Freundlich isotherm. It suggests that the mechanism can be a chemical adsorption process onto the surface binding sites of the adsorbent. The kinetic modeling of the $\mathrm{CR}$ and SF onto the composite indicates that the adsorption process fits into pseudo-second-order kinetics with a correlation coefficient higher than 0.9 . The removal percentage and adsorption capacity of CR was higher than that of cationic dye SF over a wide range of aqueous concentrations by the APC. Thus, the results suggest that the APC could be a potential adsorbent for the removal of anionic dyes from aqueous solution.

\section{Data Availability}

No data were used to support this study.

\section{Conflicts of Interest}

The authors declare that there are no conflicts of interest regarding the publication of this paper.

\section{Authors' Contributions}

V. Karthik and N. Sivarajasekar were responsible for methodology, project administration, and supervision. P. Selvakumar framed the conceptualization, investigation, and writing of the original draft. P. Megavarshini, N. Brinda, and J. Kiruthika performed the experiment and wrote the original draft. K. Balasubramani involved in methodology, supervision, reviewing, and editing. Tansir Ahamad and Mu. Naushad carried out reviewing and editing.

\section{Acknowledgments}

The authors are grateful to the Researchers Supporting Project number RSP-2020/6, King Saud University, Riyadh, Saudi Arabia, for the support.

\section{References}

[1] K. O. Adebowale, B. I. Olu-owolabi, and E. C. Chigbundu, "Removal of safranin-O from aqueous solution by adsorption onto kaolinite clay," Journal of Encapsulation and Adsorption Sciences, vol. 4, no. 3, pp. 89-104, 2014.

[2] A. B. Albadarin, M. N Collins, M. Naushad, S. Shirazian, and C. Mangwandi, "Activated lignin-chitosan extruded blends for efficient adsorption of methylene blue," Chemical Engineering Journal, vol. 307, pp. 264-272, 2017.

[3] E. Bulut and İ. A. Şengil, "Adsorption of malachite green onto bentonite: equilibrium and kinetic studies and process design," Microporous and Mesoporous Materials, vol. 115, no. 3, pp. 234-246, 2008.

[4] V. J. Sharavanan, M. Sivaramakrishnan, N. Sivarajasekar et al., "Pollutants inducing epigenetic changes and diseases," Environmental Chemistry Letters, vol. 18, no. 2, pp. 325-343, 2020.

[5] Y.-F. Hao, L.-G. Yan, H.-Q. Yu et al., "Comparative study on adsorption of basic and acid dyes by hydroxy-aluminum pillared bentonite," Journal of Molecular Liquids, vol. 199, pp. 202-207, 2014.

[6] M. El Haddad, R. Slimani, R. Mamouni, M. R. Laamari, S. Rafqah, and S. Lazar, "Evaluation of potential capability of calcined bones on the biosorption removal efficiency of safranin as cationic dye from aqueous solutions," Journal of the Taiwan Institute of Chemical Engineers, vol. 44, no. 1, pp. 13-18, 2013.

[7] T. A. Saleh and V. K. Gupta, "Photo-catalyzed degradation of hazardous dye methyl orange by use of a composite catalyst consisting of multi-walled carbon nanotubes and titanium dioxide," Journal of Colloid And Interface Science, vol. 371, no. 1, pp. 101-106, 2012.

[8] M. Sulak, E. Demirbas, and M. Kobya, "Removal of Astrazon Yellow 7GL from aqueous solutions by adsorption onto wheat bran," Bioresource Technology, vol. 98, no. 13, pp. 2590-2598, 2007.

[9] V. K. Gupta, A. Mittal, R. Jain, M. Mathur, and S. Sikarwar, "Adsorption of Safranin-T from wastewater using waste materials- activated carbon and activated rice husks," Journal of Colloid and Interface Science, vol. 303, no. 1, pp. 80-86, 2006.

[10] N. Sivarajasekar, K. Balasubramani, R. Baskar, S. Sivamani, and I. Ganesh Moorthy, "Eco-friendly acetaminophen sequestration using waste cotton seeds: equilibrium, optimization and validation studies," Journal of Water Chemistry and Technology, vol. 40, no. 6, pp. 334-342, 2018.

[11] W. Bran, "Rice husk ash as a low cost adsorbent for the removal of methylene blue and congo red in aqueous phases," Clean-Soil Air Water, vol. 37, no. 7, pp. 581-591, 2009.

[12] M. T. Yagub, T. K. Sen, S. Afroze, and H. M. Ang, "Dye and its removal from aqueous solution by adsorption: a review," Advances in Colloid and Interface Science, vol. 209, pp. 172184, 2014.

[13] C. Namasivayam and D. Kavitha, "Removal of congo red from water by adsorption onto activated carbon prepared from coir pith, an agricultural solid waste," Dyes and Pigments, vol. 54, no. 1, pp. 47-58, 2002.

[14] A. Regti, A. El Kassimi, M. R. Laamari, and M. El Haddad, "Competitive adsorption and optimization of binary mixture of textile dyes: a factorial design analysis," Journal of the Association of Arab Universities for Basic and Applied Sciences, vol. 24, no. 1, pp. 1-9, 2017. 
[15] A. Regti, M. R. Laamari, S.-E. Stiriba, and M. El Haddad, "Potential use of activated carbon derived from Persea species under alkaline conditions for removing cationic dye from wastewaters," Journal of the Association of Arab Universities for Basic and Applied Sciences, vol. 24, no. 1, pp. 10-18, 2017.

[16] P. Asaithambi, R. Govindarajan, M. Busier Yesuf, P. Selvakumar, and E. Alemayehu, "Enhanced treatment of landfill leachate wastewater using sono (US)-ozone $\left(\mathrm{O}_{3}\right)$ electrocoagulation(EC) process: role of process parameters on color, COD and electrical energy consumption," Process Safety and Environmental Protection, vol. 142, pp. 212-218, 2020.

[17] A. Regti, M. R. Laamari, S.-E. Stiriba, and M. E. Haddad, "Removal of Basic Blue 41 dyes using Persea americana-activated carbon prepared by phosphoric acid action," International Journal of Industrial Chemistry, vol. 8, no. 2, pp. 187-195, 2017.

[18] N. Sivarajasekar, K. Balasubramani, N. Mohanraj et al., "Fixed-bed adsorption of atrazine onto microwave irradiated Aegle marmelos Correa fruit shell: statistical optimization, process design and breakthrough modeling," Journal of Molecular Liquids, vol. 241, pp. 823-830, 2017.

[19] N. Sivarajasekar, N. Mohanraj, K. Balasubramani et al., "Optimization, equilibrium and kinetic studies on ibuprofen removal onto microwave assisted-activated Aegle marmelos correa fruit shell," Desalination and Water Treatment, vol. 84, pp. 48-58, 2017.

[20] D. N. Ahmed, L. A. Naji, A. A. H. Faisal, N. Al-Ansari, and M. Naushad, "Waste foundry sand/MgFe-layered double hydroxides composite material for efficient removal of Congo red dye from aqueous solution," Scientific Reports, vol. 10, pp. 2042-2053, 2020.

[21] M. Naushad, A. A. Alqadami, Z. A. AlOthman, I. H. Alsohaimi, M. S. Algamdi, and A. M. Aldawsari, "Adsorption kinetics, isotherm and reusability studies for the removal of cationic dye from aqueous medium using arginine modified activated carbon," Journal of Molecular Liquids, vol. 293, p. 111442, 2019.

[22] A. Mahapatra, B. G. Mishra, and G. Hota, "Adsorptive removal of congo red dye from wastewater by mixed iron oxidealumina nanocomposites," Ceramics International, vol. 39, no. 5, pp. 5443-5451, 2013.

[23] K. M. Mostafa, A. R. Samarkandy, and A. A. El-Sanabary, "Preparation of poly (DMAEM)-cross linked pregelled starch graft copolymer and its application in waste water treatments," Carbohydrate Polymers, vol. 86, no. 2, pp. 491-498, 2011.

[24] K. M. Mostafa, A. R. Samarkandy, and A. A. El-Sanabary, "Removal of basic dyes from aqueous medium using novel poly (MAA)-cross linked pregelled starch graft copolymer," Journal of Applied Polymer Science, vol. 118, no. 5, pp. 2728-2735, 2010.

[25] K. M. Mostafa and A. A. El-Sanabary, "Synthesis and characterization of novel smart flocculant based on poly (MAam)-pregelled starch graft copolymers and their degraded products," Advances in Polymer Technology, vol. 32, no. 2, p. 21339, 2013.

[26] M. Naushad, G. Sharma, and Z. A. Alothman, "Photodegradation of toxic dye using Gum Arabic-crosslinked-poly(acrylamide)/ $\mathrm{Ni}(\mathrm{OH})_{2} / \mathrm{FeOOH}$ nanocomposites hydrogel," Journal of Cleaner Production, vol. 241, p. 118263, 2019.

[27] J. Mohanraj, D. Durgalakshmi, S. Balakumar et al., "Low cost and quick time absorption of organic dye pollutants under ambient condition using partially exfoliated graphite," Journal of Water Process Engineering, vol. 34, p. 101078, 2020.

[28] V. Ranjithkumar, S. Sangeetha, and S. Vairam, "Synthesis of magnetic activated carbon $/ \alpha-\mathrm{Fe}_{2} \mathrm{O}_{3}$ nanocomposite and its application in the removal of acid yellow 17 dye from water," Journal of Hazardous Materials, vol. 273, pp. 127-135, 2014.

[29] S. Dawood and T. K. Sen, "Removal of anionic dye congo red from aqueous solution by raw pine and acid-treated pine cone powder as adsorbent: equilibrium, thermodynamic, kinetics, mechanism and process design," Water Research, vol. 46, no. 6, pp. 1933-1946, 2012.

[30] R. F. Mehmood, F. Mehmood, J. Akhtar, S. S. Shah, and M. A. Khosa, "Adsorption of Cd(II) by sol-gel silica doped withN-(dipropylcarbamothioyl)thiophene-2-carboxamide," Journal of Dispersion Science and Technology, vol. 34, no. 2, pp. 153-160, 2013.

[31] S. Alam, N. Rehman, A. Noor Ul, L. A. Shah, I. Mian, and H. Ullah, "Removal of basic green 5 by carbonaceous adsorbent: adsorption kinetics," Bulletin of the Chemical Society of Ethiopia, vol. 31, no. 3, pp. 411-422, 2018.

[32] S. Preethi, A. Sivasamy, S. Sivanesan, V. Ramamurthi, and G. Swaminathan, "Removal of safranin basic dye from aqueous solutions by adsorption onto corncob activated carbon," Industrial \& Engineering Chemistry Research, vol. 45, no. 22, pp. 7627-7632, 2006.

[33] A. Navya, S. Nandhini, S. Sivamani, G. Vasu, N. Sivarajasekar, and A. Hosseini-Bandegharaei, "Preparation and characterization of cassava stem biochar for mixed reactive dyes removal from simulated effluent," Desalination and Water Treatment, vol. 189, pp. 440-451, 2020.

[34] S. Muthusaravanan, S. V. Priyadharshini, N. Sivarajasekar et al., "Optimization and extraction of pharmaceutical micropollutant-norfloxacin using emulsion liquid membranes," Desalination and Water Treatment, vol. 156, pp. 238-244, 2019.

[35] K. Balasubramani, N. Sivarajasekar, and M. Naushad, "Effective adsorption of antidiabetic pharmaceutical (metformin) from aqueous medium using graphene oxide nanoparticles: equilibrium and statistical modelling," Journal of Molecular Liquids, vol. 301, Article ID 112426, 2020.

[36] S. Muthusaravanan, N. Sivarajasekar, J. S. Vivek et al., "Phytoremediation of heavy metals: mechanisms, methods and enhancements," Environmental Chemistry Letters, vol. 16, no. 4, pp. 1339-1359, 2018.

[37] B. Hameed, A. Din, and A. Ahmad, "Adsorption of methylene blue onto bamboo-based activated carbon: kinetics and equilibrium studies," Journal of Hazardous Materials, vol. 141, no. 3, pp. 819-825, 2007.

[38] J.-x. Yu, X.-l. Cai, L.-y. Feng et al., "Synergistic and competitive adsorption of cationic and anionic dyes on polymer modified yeast prepared at room temperature," Journal of the Taiwan Institute of Chemical Engineers, vol. 57, pp. 98-103, 2015.

[39] Y. Zhang, D. Qian, D. Wu, and X. Ma, "Magnetic halloysite nanotubes/iron oxide composites for the adsorption of dyes," Chemical Engineering Journal, vol. 168, no. 2, pp. 959-963, 2011.

[40] X. Yao, Z. Huang, L. Chen et al., "Alumina-nickel composites densified by spark plasma sintering," Materials Letters, vol. 59, no. 18, pp. 2314-2318, 2005.

[41] C. E. H. Bawn, "The adsorption of gases and vapors on plane surfaces," Journal of the American Chemical Society, vol. 54, no. 1, pp. 72-86, 1932. 
[42] C. Mahamadi and T. Nharingo, "Utilization of water hyacinth weed (Eichhornia crassipes) for the removal of $\mathrm{Pb}(\mathrm{II}), \mathrm{Cd}(\mathrm{II})$ and $\mathrm{Zn}$ (II) from aquatic environments: an adsorption isotherm study," Environmental Technology, vol. 31, no. 11, pp. 1221-1228, 2010.

[43] P. Taylor, M. Foroughi-dahr, and H. Abolghasemi, "Adsorption characteristics of congo red from aqueous solution onto tea waste," Chemical Engineering Communications, vol. 202, no. 2, pp. 37-41, 2014.

[44] P. N. Palanisamy, A. Agalya, and P. Sivakumar, "Polymer composite-a potential biomaterial for the removal of reactive dye," E-journal of Chemistry, vol. 9, no. 4, pp. 1823-1834, 2012.

[45] W. C. Wanyonyi, J. M. Onyari, and P. M. Shiundu, "Adsorption of congo red dye from aqueous solutions using roots of Eichhornia crassipes: kinetic and equilibrium studies," Energy Procedia, vol. 50, pp. 862-869, 2014.

[46] I. J. Idan and T. S. Y. Choong, "Equilibrium, kinetics and thermodynamic adsorption studies of acid dyes on adsorbent developed from kenaf core fiber," Adsorption Science \& Technology, vol. 36, no. 12, pp. 694-712, 2018.

[47] A. Sharma, N. Verma, A. Sharma, D. Deva, and N. Sankararamakrishnan, "Iron doped phenolic resin based activated carbon micro and nanoparticles by milling: synthesis, characterization and application in arsenic removal," Chemical Engineering Science, vol. 65, no. 11, pp. 3591-3601, 2010.

[48] Y. S. Ho and G. McKay, "Pseudo-second order model for sorption processes," Process Biochemistry, vol. 34, no. 5, pp. 451-465, 1999.

[49] E. Demirbas, M. Kobya, and M. T. Sulak, "Adsorption kinetics of a basic dye from aqueous solutions onto apricot stone activated carbon," Bioresource Technology, vol. 99, no. 13, pp. 5368-5373, 2008.

[50] E. N. El Qada, S. J. Allen, and G. M. Walker, "Adsorption of basic dyes from aqueous solution onto activated carbons," Chemical Engineering Journal, vol. 135, no. 3, pp. 174-184, 2008.

[51] V. Karthik, N. Sivarajasekar, V. C. Padmanaban, E. Nakkeeran, and N. Selvaraju, "Biosorption of xenobiotic reactive black $\mathrm{B}$ onto metabolically inactive $T$. harzianum biomass: optimization and equilibrium studies," International Journal of Environmental Science and Technology, vol. 16, no. 7, pp. 3625-3636, 2019.

[52] G. Z. Kyzas, M. Kostoglou, and N. K. Lazaridis, "Relating interactions of dye molecules with chitosan to adsorption kinetic data," Langmuir, vol. 26, no. 10, pp. 9617-9626, 2010.

[53] V. Karthik, K. Saravanan, C. Patra, B. Ushadevi, S. Vairam, and N. Selvaraju, "Biosorption of acid yellow 12 from simulated wastewater by non-viable $T$. harzianum: kinetics, isotherm and thermodynamic studies," International Journal of Environmental Science and Technology, vol. 16, no. 11, pp. 6895-6906, 2019.

[54] P. Senthil Kumar, S. Ramalingam, C. Senthamarai, M. Niranjanaa, P. Vijayalakshmi, and S. Sivanesan, "Adsorption of dye from aqueous solution by cashew nut shell: studies on equilibrium isotherm, kinetics and thermodynamics of interactions," Desalination, vol. 261, no. 1-2, pp. 52-60, 2010.

[55] V. Vimonses, S. Lei, B. Jin, C. W. K. Chow, and C. Saint, "Kinetic study and equilibrium isotherm analysis of congo red adsorption by clay materials," Chemical Engineering Journal, vol. 148, no. 3, pp. 354-364, 2009.
[56] J. Mohammed, U. I. Noah, I. Jibrin, K. S. Madaki, and S. I. Audu, "Equilibrium, kinetics and thermodynamic studies on the removal of safranin-O from waste water using activated carbons derived from coconut shell and pineapple peel," American Journal of Physical Chemistry, vol. 8, no. 1, pp. 1-10, 2019.

[57] N. Laskar and UpendraKumar, "Adsorption of safranin (cationic) dye from water by Bambusa tulda: characterization and ANN modeling," Environmental Engineering Science, vol. 35, no. 12, pp. 1-15, 2018.

[58] S. Chowdhury, R. Mishra, P. Kushwaha, and P. Saha, "Removal of safranin from aqueous solutions by $\mathrm{NaOH}$-treated rice husk: thermodynamics, kinetics and isosteric heat of adsorption," Asia-Pacific Journal of Chemical Engineering, vol. 7, no. 2, pp. 236-249, 2010.

[59] A. Tyagi, S. Das, and V. C. Srivastava, "Removal of toxic hydroquinone: comparative studies on use of iron impregnated granular activated carbon as an adsorbent and catalyst," Environmental Engineering Research, vol. 24, no. 3, pp. 474483, 2018. 